April 25, 1865.

JOHN ROBINSON M‘CLEAN, President, in the Chair.

No. 1,110._- "On Uniform Stress in Girder Work, illustrated by reference to two Bridges recently built." By CALLCOTT REILLY, Assoc. Inst. C.E.

\title{
Section I.-Introduction.
}

The general principles governing the design and construction of girders, and the merits of different classes of beams, have been so often discussed at the Meetings of the Institution, and in the works of eminent writers on engineering mechanics, that the Author feels great diffidence in bringing forward a Paper professing to deal with a special abstract principle. The general laws and the methods of their application have been settled and universally accepted, and there remains, therefore (as was well observed at the Institution two years ago) only the minutia of the subject of girder work, upon which any useful discussion can take place, and the Author proposes to submit some of those minutiæ, about which, apparently, a difference of opinion still exists.

In the course of a discussion ${ }^{2}$ at the Institution in 1863, Mr. Phipps, M. Inst. C.E., suggested the importance of considering, in the design of girders, more especially of triangular truss-girders, the condition of what Professor Rankine calls "uniform stress" At the same time, he condemned the trough-shaped section, commonly adopted for the top and bottom members of truss-girders, because the intensity per square unit of the stress upon any vertical cross section is necessarily variable, when the connection of the vertical web with the trough is made in the usual manner; being greatest at the edges of the sides of the trough, and least at the outer surface of its bottom, where the mass of the material is chiefly accumulated.

The Author, in order to justify to some extent, his proposing this subject for further consideration, desires to refer briefly to the difference of opinion exhibited on that occasion. Some of the speakers, although agreeing with Mr. Phipps in principle, thought

1 The discussion upon this Paper extended over portions of three evenings, but an abstract of the whole is given consecutively.

2 Fide Minutes of Proceedings Inst. C.E., vol. xxii., p. 528 et seq. 
that the use of the trough was justified by its great convenience; while others, equally qualified by their experience and attainments in this department, considered the trough-shaped section was right in principle, on the ground that by its use, the greatest quantity of material is concentrated at the points where failure is most likely to begin. This opinion is probably the one most prevalent among those whose ousiness it is to design or manufacture girder work for bridges. Convinced that Mr. Phipps's views were correct in principle, and easy of application, the Author has been allowed by Mr. Edward Woods, M. Inst. C.E., to embody his conclusions in the design of several railway bridges, now completed or in course of completion, under the direction of Mr. Woods as Engineer-in-chief; and by his permission he is enabled to submit to the Institution a description of two of these bridges, for the purpose of illustrating the application of the principle now proposed for consideration.

These bridges are of no importance as regards their magnitude or difficulty of construction. The situation and the masonry call for no special remark in either case, therefore attention is invited to the construction of the ironwork only, and chiefly to those details which were designed with the object of carrying out, as nearly as possible, in every part of the girders, the condition of uniform stress.

Before proceeding to describe these details it may be useful, in order to gain fixed ideas, to quote, as shortly as possible, Professor Rankine's definition of "uniform stress."

The words "strain" and "stress" are used indifferently in popular language to denote the same thing; but Professor Rankine, in his book on "Applied Mechanics," has adopted a distinction, which is worthy of general acceptance on the ground of perspicuity. "Stress" is there defined as a force exerted between two bodies at their surface of contact, or between two parts, into which the same body may be conceived to be divided by a plane of section passing through it in any given direction. Stress may be either a tensile force, a compressive force, or a shearing force, and is distributed over the surface of contact, or over the plane of section, as the case may be. On the other hand, the word "strain" is defined as the alteration of figure and volume of a solid body, and of its parts, produced by the action of stress as just defined. The "centre of stress" or "centre of pressure" in any surface, is the point traversed by the resultant of the whole stress, that is, the centre of parallel forces for the whole stress. If the intensity of stress per square unit of the surface on which it acts be uniform, the centre of stress must coincide with the centre of gravity of that surface; and conversely, if the centre of stress does not coincide with the centre of gravity, but deviates from it in a certain known direction, the stress is not a uniform stress, 
but, under certain conditions, is called "a uniformly varying stress." Its mean intensity occurs at the axis (called the neutral axis of the stress) which traverses the centre of gravity of the surface of action; and its greatest intensity occurs at that extreme edge of the surface situated on the same side of the axis as the centre of stress, and the least intensity of the stress occurs at the extreme edge situated on the opposite side of the neutral axis.

Some apology may be due for touching upon principles so elementary and well known; but, although these principles are, no doubt, elementary, the strict proof of their existence is somewhat abstruse ; and, moreover, it is only on the basis of a perfectly clear apprehension of the difference between " uniform stress " and " uniformly varying stress," that any useful argument on the present subject can be carried on.

The preceding proposition will be discussed and demonstrated in the concluding part of the Paper. The Author will, therefore, for the present, assume it to be true. Taking also as an axiom, that failure of any member of a girder, or other framework, will begin where the resistance to strain is really least, that is, where the intensity of the stress is greatest; it follows, that the opinion which upholds as right in principle the trough-shaped section as applied in the usual manner, must be a mistake. And, moreover, every form of section of any member of a girder, or framework, which does not admit of the approximate coincidence, of the centre of stress, with its centre of gravity, is liable, in degree, to the same objection.

For the sake of brevity, the Author proposes to adopt from Mr. Latham's book on "Wrought Iron Bridges," the word "boom" to denote the top and bottom members of a beam, or truss girder. Various phrases are in use for this purpose, but none appear to express so well and so concisely the functions of those members in preventing the collapse of the vertical web, somewhat as a "boom" in seafaring language, keeps stretched the sail attached to it.

The two bridges about to be described have been selected as showing different conditions of loading; No. 1 (Plates 23 and 24) carries the platform on the top, and No. 2 (Plates 25 and 26) has the platform between the main girders near the bottom. Notwithstanding that, as before remarked, the merits of different classes of trusses constitute a question, that having been so frequently discussed, is by this time somewhat threadbare, the Author hopes that he will be pardoned for reviving even this hackneyed subject, having to describe the peculiarities of two wrought-iron girder bridges which show an economy of material in the main girders, that, so far as his information enables him to judge, is not common, at least in this country. In seeking for the causes of this economy, it will be necessary briefly to compare the forms of truss chosen with other forms more usually adopted. No. 1 bridge exhibits a pair of trusses 
93 feet 4 inches span between the bearings, designed to carry, in addition to the fixed load, a moving railway load of 1 ton per foot of span for a single line of way, with a maximum intensity of stress of 5 tons per square inch of tension, and $3 \frac{1}{2}$ tons per square inch of compression; and the total weight of wrought iron in the framework of the pair of trusses is 18 tons. The cast-iron saddles rivetted on at the ends weigh $4 \frac{1}{2} \mathrm{cwt}$. each ; if these be included, the weight of iron, both wrought and cast, in the pair of trusses is under 4 cwt. per lineal foot of span. ${ }^{1}$

No. 2 bridge is 80 feet span between the bearings: it is designed to carry, in addition to the fixed load, a moving load of $1 \frac{7}{8}$ ton per foot of single line of railway at the same maximum intensity of stress as No. 1; and the total weight of wrought iron in the pair of trusses is 20 tons 18 cwt. The cast-iron saddles rivetted on at the ends weigh $5 \frac{1}{2} \mathrm{cwt}$. each; if these be included, the weight of iron, both wrought and cast, in the pair of trusses is 22 tons, being at the rate of $5 \frac{1}{2}$ cwt. per lineal foot of span. ${ }^{2}$ 'This weight is greater than that of No. 1, although the span is less, but the intensity of the assumed possible moving load is 87 per cent. greater; and the roadway lying between the trusses instead of on the top, its weight is necessarily much greater; the cross-girders are much heavier, each being adapted to support separately the heaviest load brought on by a driving axle weighted with 16 tons; the moving load thus brought upon each cross girder, and to which its strength is proportioned, is 18 tons, equal to $2 \frac{1}{4}$ tons per foot of span of bridge. The trusses of No. 2 bridge have therefore a greater strength than is usual even in this country, and the preceding circumstances being borne in mind, their economy of material is even more striking than that of the trusses of No. 1 .

No. 1 bridge is built to carry the single line of the "Central Argentine Railway" over the River Desmochado, or Carcarañal, about 30 miles to the westward of the town of Rosario, in the Argentine Republic. No. 2 bridge, built also for a single line of

1 The gross fixed load per epan of this bridge is $36 \cdot 16$ tons, of which 22.43 tons is iron in main trusses, cross-girders, cross-girder saddles, and bracing; 11.23 tons timber and fastenings, and $2 \cdot 5$ tons permanent way. The above weight of ironwork is exclusive of bed-plates, rollers, \&c., resting entirely on the piers. Including these items, the gross weight of ironwork, per square span, is $2 \tilde{5} \cdot 2$ tons, not ineluding bolts and spikes for fastening timber and permanent way.

2 The gross fixed load of this bridge, per span, is 50 tons, of which 30.4 tons is iron in main trusses, cross-girders, and bracing; 10.25 tons timber and fastenings, $6 \cdot 8$ tons ballast, and 2.5 tons permanent way. The above weight of iron-work is exclusive of bed-plates and rollers. It is reduced to a square bridge, and the description and calculations throughout refer to a square bridge for the sake of simplicity. The actual bridge over the Wey and Arun Canal is, however, built on a very sharp anglo of askew, and conscquently the quantity of inaterial actually put into that bridge is nearly 5 per cent. greater than given above, the differeuce beng entircly in the cross-girders und platform. 
way, carries the "Horsham and Guildford Railway" over the Wey and Arun Canal, in the county of Surrey, about 5 miles to the south of Guildford.

\section{Section II.-Comparison with Ordrnary Forms of Truss.}

The particular form of truss chosen has not been much used in this country; it was suggested by the description, in a paper "On American Iron Bridges," by Mr. Zerah Colburn, M. Inst. C. E., read in the year 1863, of what is extensively known in the United States as the "Murphy Whipple truss ;" and it was selected by Mr. Woods, after comparison with other systems, as perhaps, upon the whole, the most economical form in which the material could be arranged to obtain a given strength; and also, in the case of No. 2 bridge, because it seemed to afford the greatest facilities for a satisfactory connection with the cross girders, when, as in that bridge, the line of road passes between the trusses.

The former ground of preference, being directly at variance with influential opinions expressed during the discussion on $\mathrm{Mr}$. Colburn's paper, it is proposed to explain it somewhat in detail, by means of a more exact comparison than was attempted on that occasion. Skeleton diagrams are exhibited, comparing each of the trusses selected with two equivalent trusses, of the types generally used in this country; the various circumstances of ratio of depth to span, which is as $1: 10$, and application and distribution of load, and consequently the number and position of the loaded joints, being common to the three trusses which are the subject of this comparison.

Diagram No. 1 (Plate 27) exhibits the centre lines of the various bars composing the truss adopted for No. 1 bridge, in which the struts are vertical, and the ties inclined to the horizon at $45^{\circ}$; Nos. $1_{A}$ and $1_{B}$ show, in the same manner, the centre lines of two equivalent trusses; the former being the ordinary Warren truss, the diagonal bars of the web being at an angle of $63^{\circ} 26^{\prime}$ with the horizon, this angle being the one prescribed by the circumstances just mentioned. No. $1_{\mathrm{B}}$ is the ordinary diagonal truss in its simplest form, with two sets of triangles, the bars of the web crossing at the angle of $45^{\circ}$.

The method of comparison adopted is that used, it will be remembered, with such excellent effect by Mr. Bramwell, M. Inst. C.E., in discussing the relative weight of material in the trusses of the various American iron bridges described in Mr. Colburn's Paper, before alluded to.

The equal loads, concentrated upon the loaded joints of the trusses, are represented by the blackened circles; the compressed bars by thick lines, and the bars subject to tension by thin lines.

${ }^{3}$ Vide Minutes of Proceedings Inst. O.E., vol. xxii., p. 540. 
The depth of the truss is taken as the unit of length; and the unit of force and of weight is the load carried by each loaded joint. 'The plain figures adjacent to the bars of the web, are the several units of load vertically ${ }^{1}$ supported by those bars, on the supposition that the whole load is fixed, and uniformly distributed among the loaded joints.

The underlined figures show the greatest number of units of load vertically carried by each bar, supposing the entire load to be a moving load of uniform intensity, travelling from one end of the truss towards the opposite end.

The plain figures written upon each of the horizontal bars of the two "booms" in each diagram, express, in terms of the unit of load, the greatest total stress upon that bar, the stress being greatest when the whole load is equally distributed among all the loaded joints : these figures, in the case of any particular bar, are therefore the sum of the horizontal components of the stresses upon those bars of the web which lie between that bar and the nearest end of the truss, and are deduced from the plain figures written upon the bars of the web. The bracketted figures will be explained hereafter. For the sake of simplifying the comparison, the intensity per square unit of the tension and compression will be assumed as equal.

From a brief consideration of these figures, the weight of each truss will now be deduced, discarding for the present all circumstances relating to the stiffening of the parts in compression, and to the practical exigencies of construction; it will be necessary, afterwards, to take some of these into account, in order to arrive at a reliable reason for preferring one truss to another.

Diagram No. 1.-The aggregate stress upon the left-hand half of the top boom, being the sum of the plain figures upon the five bars composing it, is

$\times \frac{4}{2}$ units,

Gives for the whole truss $\overline{95}$,

And as the length of each bar is 1 unit, being equal to the depth of the truss, the weight of the top boom is proportional to the number 95 .

Next as to the struts: The maximum number of units of load carried by the four and a half struts comprised in one half of the truss, being the sum of the underlined figures, is,

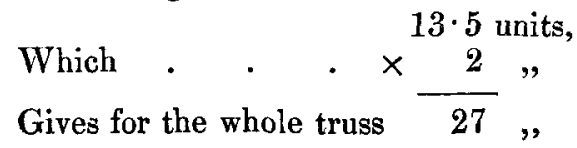

' In the case of the diagonal bars the figures represent the vertical components. 
The struts being vertical, the unit of load is also the unit of stress; and as the length of each bar is unity, the weight of all the struts is proportional to the number 27 . 'The total weight of the compressed members of the truss is therefore proportional to

$$
95+27=122 .
$$

The aggregate stress upon one half of the lower boom, being the sum of the plain figures written thereon, is

. 35 units, which $\times 2$

gives for the whole truss $. \quad . \overline{70}$

The weight of the lower boom is therefore proportional to the number 70 .

The maximum number of units of load carried vertically by the diagonal ties, being the sum of the underlined figures, is for the half truss

$$
\text { gives for both halves . . } 29 \text { ", }
$$

The angle of inclination being $45^{\circ}$, the ratio of stress to load is $\sqrt{ } 2$, and the length of each tie is also $\sqrt{ } 2$; therefore the weight of all the ties is proportional to $29 \times 2=58$.

The total weight of the parts subject to tension is therefore proportional to.

to which add the weight in compression $70+58=128$ units,

$$
\text { giving . . . . . } \frac{122}{250} "
$$

as the number proportional to the total theoretical weight of truss No. 1.

Diagram No. $1_{A}$. -The same method of reasoning applied to this truss gives for the weight of the top boom ${ }^{1}$. . . $\quad 82 \cdot 5$ units, of the struts ${ }^{2}$. . . . . 36.25 , giving the weight of all the parts in compression proportional to

The weight of the lower boom ${ }^{3}$ is also expressed by . . . $82 \cdot 50$ units, and of the ties by . . . $36 \cdot 25$, the whole weight in tension being proportional to $\cdot$. The theoretical weight of truss No. $]_{A}$ is therefore proportional to $118 \cdot 75$ units.

1 Thus, $(2 \cdot 25+6 \cdot 25+9 \cdot 25+11 \cdot 25+12 \cdot 25) \times 2=82 \cdot 5$

$2(4 \cdot 5+3 \cdot 6+2 \cdot 8+2 \cdot 1+1 \cdot 5) \times 2 \times\left(\right.$ cosec. $^{2} 63^{\circ} 26^{\prime}$, or $\left.1 \cdot 25\right)=36 \cdot 25$.

$3\left(4 \cdot 5+8+10 \cdot 5+12+\frac{12 \cdot 5}{2}\right) \times 2=82 \cdot 5$.

${ }^{4}(4 \cdot 5+3 \cdot 6+2 \cdot 8+2 \cdot 1+1 \cdot 5) \times 2 \times\left(\right.$ cosec. $^{2} 63^{\circ} 26^{\prime}$, or $\left.1 \cdot 25\right)=36 \cdot 25$. 
Diagram No. $1_{B}$. - In this truss the proportional weight of the top boom ${ }^{1}$ is . . . . 80 units, of the struts ${ }^{2}$. . . . $36 \cdot 8$, giving the weight of all the parts in compression proportional to

The weight of the lower boom ${ }^{3}$ is proportional to that of the ties to The whole weight in tension is thus proportioned to And the theoretical weight of truss No. $1_{\mathrm{B}}$ is therefore proportional to

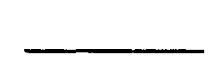

$116 \cdot 8$ units.

85. units, $25 \cdot 2$

In this preceding comparison the weight of joints and stiffening is not included; the former may no doubt be taken as about equal for all the trusses, but the case is otherwise with the stiffening required for the parts in compression; and in trusses of much greater span and depth than those under consideration, the weight of this stiffening would be a considerable item. The Author will therefore attempt to deduce from the weight of stiffening actually put into the struts of No. 1, the comparative weights required for the other two trusses, postponing, for the present, the consideration of that required for the end pillars of No. $1_{B}$, and for the top booms of all the trusses.

The actual aggregate weight of the transverse stiffening in the struts of No. 1 truss is $1,060 \mathrm{lbs} .{ }^{5}$ which is assumed to be the least that is possible. ${ }^{6}$ The theoretical weight of the struts without stiffening, taking the intensity of the compressive stress at $3 \frac{1}{2}$ tons per square inch, is $1,637 \mathrm{lbs}$., which, as before shown, is

$(2+6+9+11+12) \times 2=80$.

$2(2 \cdot 5+2+1 \cdot 6+1 \cdot 2+0 \cdot 9) \times 2 \times\left(\operatorname{cosec}^{2} 45^{\circ}\right.$, or 2$)+4=36 \cdot 8$.

$3(2 \cdot 5+6 \cdot 5+9 \cdot 5+11 \cdot 5+12 \cdot 5) \times 2=85$.

$4(2+1 \cdot 6+1 \cdot 2+0.9+0 \cdot 6) \times 2 \times\left(\operatorname{cosec}^{2} 45^{\circ}\right.$, or 2$)=25 \cdot 2$.

5 The stiffening to each strut comprises 14 diagonal bracing-bars 2 in. $\times \frac{3}{8}$ in. $\times 1.7$ foot long, and weighing 60 lbs, and 40 feet run of $1 \frac{3}{4}$ in, $\times \frac{2}{4}$ in. bar, being the transverse limbs of the vertical angle-irons, and weighing $58 \mathrm{lbs}$. In all 118 lbs. per strut; which, multiplied by 9 struts, gives, say 1,060 lbs. The remaining section of the $2 \mathrm{in} . \times 2$ in. $\times \frac{1}{4}$ in, angle-irons, is calculated as part of the compressed sides of the strut. See pp. 401 and 411, and Plate 24, Fig. 2.

6 The possibility here is not proved; that can only be done hy special experiments, which the Author has not had the opportunity of making. The bracingbars, which contain the greater part of the material expended in stiffening the struts in the two trusses numbered 1 and 2 , are considerably lighter than what are commonly used in struts of similar construction; but there is no proof that lighter ones still would have been insufficient. Moreover, the additional material required for stiffening longer struts might be more judiciously added to the compressed sides of the struts, than to the bracing-bars. Again, it may be reasonably urged that an addition to the width of the strut would be a more economical way of obtaining the desired stiffness. 
proportional to 27 units of weight. The weight of the stiffening is consequently proportional to $17 \cdot 4$ units of weight. ${ }^{1}$

In order to make an exact comparison of the preceding, with the weights required for Nos. $1_{A}$ and $1_{B}$, the following fundamental principle deduced by Mr. Lewis Gordon from Hodgkinson's experiments on long pillars ${ }^{2}$ is quoted. "In long struts, the additional stress due to bending is to the stress due to direct pressure in a ratio which increases as the square of the proportion in which the length exceeds the diameter." 3

From this theorem the following conclusion may, it is thought, be reasonably inferred :- "In long struts of equal width, the strength of the stiffening necessary to resist the stress due to bending, varies as the pressure upon the struts, and as the squares of their lengths." The weight of the stiffening will therefore vary as the cubes ${ }^{4}$ of the lengths. This particular form of the question has not, it is believed, been investigated in any text book; and it is hoped, some remarks may be made during the discussion upon this subject. By the application of this principle, the proportionate weight of the transverse stiffening necessary for the struts of Nos. $1_{A}$ and $1_{B}$, may be deduced from the known weight of that of No. 1 .

First, as to No. $1_{A}$, the sum of the vertical loads, as shown by the underlined figures, is 29 units, which multiplied by cosec. $63^{\circ} 26^{\prime}$ or $1 \cdot 118$ (the proportionate length), gives 32.4 units as the sum of the pressures. The weight of stiffening in No. 1 being $1,060 \mathrm{lbs}$, and the pressures 27 units, the stiffening in $1_{\mathrm{A}}: 1060$ $:: 32 \cdot 4: 27$, and would thus be $1,272 \mathrm{lbs}$. if the struts were the same length as in No. 1. But the length being to the length in No. 1 as $1 \cdot 118: 1$, the weight varies as $1 \cdot 118^{3}: 1$. Therefore the weight required for No. $1_{A}=1272 \times 1.4=1781 \mathrm{lbs}$. Then, as $1,060 \mathrm{lbs}$. is proportional to $17 \cdot 4$ units of weight, so the proportionate weight of the stiffening necessary for No. $1_{A}$ is 29.2 units, which is therefore to be added to the theoretical weight previously given.

In the case of truss No. $1_{13}$ the sum of the vertical loads carried by the struts, as shown by the underlined figures, is 16.4 units,

1 The weight of one unit of the greatest load, both fixed and moving, this truss was :alculated to support, is $6 \cdot 82$ tons, which multiplied by 27 , the number of units of stress upon all the struts together, and divided by $3 \cdot 5$ tons, the intensity per square inch of the compression, gives $52 \cdot 61$ square inches as the aggregate sectional area of all the struts. Then $52 \cdot 61$ multiplied by the common length of

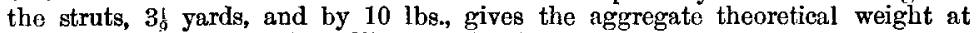
$1,637 \mathrm{lbs}$. Then, as $1637: 27:: 1060: 17 \cdot 4$.

${ }_{2}$ Rankine's "Applied Mechanics," p. 361.

3 The diameter being measured in the plane in which the bending takes place. The lateral vibration, to which the girder is liable in the transverse plane, and not in the longitudinal plane, helps to make the former the plane in which bending is most to be guarded against.

4 'The weight per unit of length being as the square, the weight per strut, being the preceding $x$ the length varies as the cube. 
which multiplied by cosec. $45{ }^{\circ}$ or $1 \cdot 414$, the proportionate length gives 23.2 as sum of pressures. The actual weight of the stiffening in No. 1 being $1,060 \mathrm{lbs}$., and the sum of pressures 27 units, the necessary stiffening in No. $1_{B}: 1060:: 23 \cdot 2: 27$, and would thus be $910 \mathrm{lbs}$. if the struts were the same length as in No. 1 ; but the length of the struts being to those of $\mathrm{No}$. 1 as $1.414: 1$, the weight varies as $1 \cdot 414^{3}$ to 1 . Therefore the weight required :910:: $2 \cdot 828: 1$, and thus amounts ${ }^{1}$ to $2,573 \mathrm{lbs}$. Then, because 1,060 is proportional to 17.4 units of weight, so the proportionate weight of stiffening requisite for No. $1_{B}$, is $42 \cdot 2$ units, ${ }^{2}$ which is therefore to be added to the theoretical weight previously given.

An inspection of the plain and underlined figures, written upon the diagrams, shows that the theoretical weight of certain bars of No. $1_{A}$, and especially so of No. $1_{B}$, is much less than any of those in No. 1 ; and the question arises, Is it possible to obtain in practice the advantage of that difference? The Author believes it to be impossible in the case of several of those bars which resist compression, while admitting the possibility of doing so in the case of all the tension bars, by adopting suitable methods of jointing.

In truss No. 1, as practically worked out, there are several bars subject to compression, the scantlings of which it was found impossible to reduce to so small a size as to be proportional to the plain and underlined figures upon the diagram. For instance, the division $\mathrm{A} \mathrm{B}$ of the top boom, consists of 4 angle-irons

$11 \cdot 414^{3}=2 \cdot 828$.

2 To show approximately the dimensions of stiffening, similarly constructed to that of the struts of No. 1, required to give the weight of 2,573 lbs., shown to be required for truss No. $1_{\mathrm{B}}$. There are ten struts, averaging $257 \mathrm{lbs}$. of stiffening to each. Each strut would be about $9 \cdot 3 \times 1 \cdot 4=13 \cdot 7$ feet long. The weight of stiffening per foot run of strut would be $\frac{257}{13 \cdot 7}=19 \mathrm{lbs}$; corresponding to the lalves of four vertical angle-irons $2 \frac{1}{2}$ in. $\times 2 \frac{1}{2}$ in. $\times \frac{5}{6} \mathrm{in} .=9.5 \mathrm{lbs}$, and two bracing-bars $1.4 \mathrm{ft}$. long $\times 23 \mathrm{in.} \times \frac{3}{8} \mathrm{in} .=9 \cdot 5 \mathrm{lbs}$, in all $19 \mathrm{lbs}$. per foot. (Fig. 1.) These dimensions are well known to be not grenter than are generally adopted in the practice of the present time.

Fig. 1.

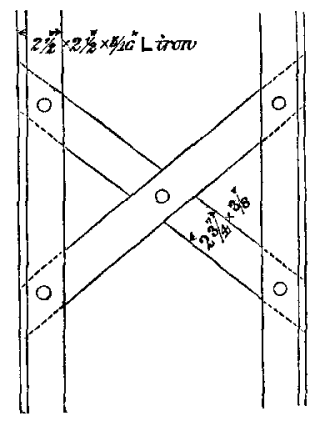


$2 \frac{3}{4}$ in. $\times 2 \frac{3}{4}$ in. $\times \frac{5}{16}$ in., connecting together one horizontal plate 16 in. wide $\times \frac{1}{4}$ in. thick, and two vertical plates $6 \frac{3}{4}$ in. wide $\times \frac{1}{4}$ in. thick, thus :-

Fig. 2.

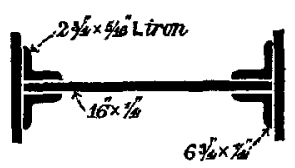

It will readily be conceded that thinner plates or angle-irons could not be used with any regard to durability, and that the stiffness requisite would not admit of less width. The sectional area available for compression is $13 \frac{1}{4}$ square inches, ${ }^{1}$ whereas the area corresponding to the $4 \frac{1}{2}$ units of stress marked upon the diagram is only 8.77 square inches, ${ }^{2}$ the unit of load and stress being 6.82 tons, and the intensity of the stress $3 \frac{1}{2}$ tons per square inch. This least practicable section corresponds to the 6.8 units $^{3}$ marked by bracketted figures upon the diagram, which is therefore proportionate to the least practicable weight of any bar of the top boom of No. 1 ; and it follows that it is also the least practicable proportionate number for $1_{\mathrm{A}}$ and $1_{\mathrm{B}}$. Similarly it was found impossible to construct any vertical strut of less scantling than corresponds to 2.26 units of load, ${ }^{4}$ on account both of the width requisite for stiffness, apart from the stiffness transverse to the length of the truss, which has been previously considered, and also to find room for the necessary rivets; and this reason would apply equally to No. $1_{A}$ and No. $1_{B}$. It follows therefore that those underlined figures written upon the struts, which are less than $2.26 \times$ sine-angle of obliquity, must in all three trusses be

${ }^{1}$ Of the horizontal plate, 16 in. $\times \frac{1}{4}$ in., $13 \cdot 6$ in. only is available for compression, the remainder being cut away at the joints of the web.

$\frac{26.82 \times 4.5}{3.5}=8.77 \mathrm{sq}$. inches.

$\begin{gathered}313.25 \text { sq. ins. } \times 3 \cdot 5 \text { tons per sq. ineh. } \\ \text { one unit }=6.82 \text { tons. }\end{gathered}=6.8$ units.

4 The section (shown by the shading in Fig. 3 ) of the lightest strut available for compression, consists of two plates 5 in. ${ }^{2} \times \frac{1}{4}$ in. $=2 \cdot 5 \mathrm{sq}$. inches, and the shaded portions of four angle-irons, 2 in. $\times 2$ in. $\times \frac{1}{4}$ in. of which is available

Fig. 3.

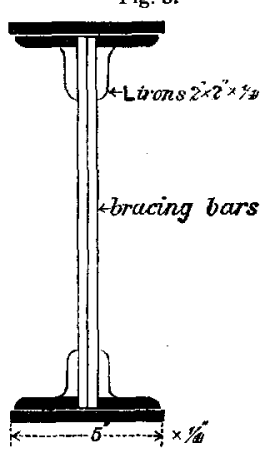


replaced by that quantity, which is accordingly marked in bracketted figures upon the diagrams. ${ }^{1}$

In the case of No. $1_{1}$, the theoretical weight of the end pillars would be increased at least fivefold in the practical construction. The sectional area corresponding to the two units of load carried by the pillar is 3.9 square inches, ${ }^{2}$ which is equal to that of a mere 4 -inch angle-iron $\frac{1}{2}$ in. thick. It is inferred from observation of the lightest existing examples, that the smallest practicable section sufficient to give the requisite stiffness, and to afford room for rivets, would not be less than $19 \frac{1}{2}$ square inches, corresponding to one transverse or diaphragm plate 16 in. wide $\times \frac{1}{4}$ in. thick, 4 angle-irons $2 \frac{3}{4}$ in. $\times \frac{5}{16}$ in. and two outer plates 12 in. wide $\times$ $\frac{3}{8}$ in. thick, as shown in horizontal section in Fig. 4 ; and even

Fig. 4.

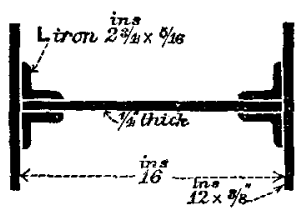

this section might reasonably be thought little enough. The number 2, which expresses the theoretical weight of one end pillar, must therefore be replaced by the number 10 marked thereon in bracketied figures.

The results of the preceding comparison between the three trusses will now stand as follows :-

\begin{tabular}{|c|c|c|c|}
\hline & No. 1. & No. $1_{\lambda}$. & No. $1_{\mathrm{B}}$. \\
\hline $\begin{array}{l}\text { Theoretical weight } \\
\text { Proportionate weight of transperse stiffening to } \\
\text { struts. } \\
\text { Fxcess of practicable minimum over theoretical } \\
\text { minimum, corresponding to the differences be- } \\
\text { tween the bracketted figures and the plain and } \\
\text { underlined figures superseded ly them }{ }^{3} \text {. }\end{array}$ & $\begin{array}{l}\text { Units. } \\
250 \\
17 \cdot 4\end{array}$ & $\begin{array}{r}\text { Units. } \\
237 \cdot 5 \\
29 \cdot 2\end{array}$ & $\begin{array}{l}\text { Units.! } \\
227 \\
42 \cdot 2\end{array}$ \\
\hline Total weiglit, exclusive of joints and packings. & $273 \cdot 58$ & $278 \cdot 2$ & $300 \cdot 8$ \\
\hline
\end{tabular}

1. Thus the least section of strut being such as will, at an intensity of $3 \frac{1}{2}$ tons, resist $2 \cdot 26$ units of stress, then in truss No. $1_{A}$, and in truss No. $\mathbf{1}_{B}$,

$2 \cdot 26$ sin. $63^{\circ} 26^{\prime}$ or $0 \cdot 894=2 \cdot 02$ units of vertical load;

$2 \cdot 26 \sin .45^{\circ}$ or $0 \cdot 707=1 \cdot 6$ unit of vertical load.

22 units $\times 6.84$ tons per unit $\div 3 \frac{1}{2}$ tons intensity of stress $=3.9$ sq. inches area of section.

3 Thus, as regards No. 1 ;

$$
2(6 \cdot 8-4 \cdot 5+2 \cdot 26-2 \cdot 1+1 \cdot 13-0 \cdot 5)=6 \cdot 18 .
$$


From this it appears that the least practicable weight of No. 1 truss is less than that of No. $1_{A}$ by 1.7 per cent. This percentage being only small, it may be said that, practically, the two trusses are equal in point of economy ; there is therefore no motive for preferring one to the other, except such as may arise from considerations of workshop convenience and facility of construction; and in those respects it is submitted that, speaking generally, No. $\mathbf{1}_{\mathrm{A}}$ has no advantage over No. 1. The advantage, in point of economy of weight, of No. 1 over No. $1_{B}$ is more decided, being 10 per cent., sufficient, it is submitted, speaking generally and without denying that special circumstances may, in particular cases, justify a choice of the heavier truss, - to entitle No. 1 to a preference over No. $1_{B}$.

Turning now to the truss selected for No. 2 bridge, it is proposed to exhibit, as briefly as possible, the results of a similar comparison between it, and two equivalent trusses of the character commonly used under the same circumstances.

Diagram No. 2 Plate 27 shows the truss chosen for No. 2 bridge, in which the tension-bars of the web are inclined at the angle of $45^{\circ}$, excepting the two endmost ones, which are vertical ; the two endmost struts are also inclined at $45^{\circ}$, but the remainder are vertical. Nos. $2_{\alpha}$ and $2_{B}$ show two equivalent trusses, exactly similar to Nos. $1_{A}$ and $1_{B}$ respectively, excepting, that as in No. 2, the load is supported at or near the bottom. The ratio of depth to span, and the units of load and stress, and of weight, are the same relatively ${ }^{1}$ as in No. 1 .

Diagram No. 2.-The theoretical weight of the top boom, is proportional to the sum of the plain figures marked thereon $\times 2$, thus $43 \times 2=$. . . $86^{\text {c }}$ 'units.

That of the struts, to the sum of the underlined figures, marked upon the vertical struts $\times 2+4 \cdot 5$ marked upon the inclined end strut $^{2} \times 4=$ giving the weight of all the parts in compression proportional to . .

$30 \cdot 8$,

$\longrightarrow 116 \cdot 8$ units.

As regards No. $1_{A}$,

$$
\begin{gathered}
2\left\{6 \cdot 8-2 \cdot 25+6 \cdot 8-6 \cdot 25+(2 \cdot 02-1 \cdot 5) \operatorname{cosec}^{2} 63^{\circ} 26^{\prime}\right\} \\
=2(5 \cdot 1+0 \cdot 52 \times 1 \cdot 25)=11 \cdot 5 .
\end{gathered}
$$

As regards No. $1_{\mathrm{R}}$,

$$
\begin{gathered}
2\left\{6 \cdot 8-2+6 \cdot 8-6+10-2+(1 \cdot 6-1 \cdot 2+1 \cdot 6-0 \cdot 9) \operatorname{cosec}^{2} 45^{\circ}\right\} \\
=2(13 \cdot 6+1 \cdot 1 \times 2)=31 \cdot 8 .
\end{gathered}
$$

1 The units of load, stress, and weight have the same relation as in No. 1; that is to say, they are all equal. But the absolute value of the unit is greater, being 10 tons.

2 The factor $4=\sqrt{ }^{2}$ for stress $\times \sqrt{ } 2$ for length $\times 2$ halves.

[1864-65. N.S.] 
The weight of the lower boom is

Brought forward .. 116.8 units. expressed by the sum of the plain figures marked thereon $\times 2$, or $39 \frac{1}{2} \times 2=$. . . . .

That of the ties, is the sum of the underlined figures marked upon the four diagonal ties $\times 4+$ the figure 1, upon the endmost vertical tie, $\times 2=$. . . . .

The weight of all the parts in tension is consequently proportional to

Adding the weight in compression, the total theoretical weight of the truss No. 2 is proportional to .

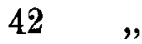

The vertical bar in the centre of the span, will be accounted for further on.

Diagram No. 2 . - A similar calculation applied to this truss, gives the theoretical weight of the top boom ${ }^{\mathrm{l}}$. . . . . $82 \cdot 5$ units of the struts ${ }^{2}$. . . . . $36 \cdot 25$, giving the weight of all the parts in compression, proportional to . .

The weight of the lower boorn ${ }^{3}$ is expressed by . . . $82 \cdot 5$ " of the ties, by : . . . . $36 \cdot 25$ " the whole weight in tension being thus proportional to . . . The theoretical weight of truss No. $2_{\mathrm{A}}$ is therefore proportional to $118 \cdot 75$ units

121, $237 \cdot 8$

Diagram No. $2_{\mathrm{B}}$ (Plate 27).-The proportionate weight of the top boom is . . . . . 85 units of the struts ${ }^{5}$. . . . . . 30.2 ", the whole weight in compression being thus proportional to

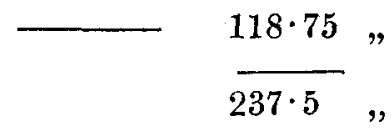

1 Thus, $2\left(4 \cdot 5+8+10 \cdot 5+12+\frac{12 \cdot 5}{2}\right)=82 \cdot 5$.

$2(4 \cdot 5+3 \cdot 6+2 \cdot 8+2 \cdot 1+1 \cdot 5) \times 2 \times\left(\operatorname{cosec}^{2} 63^{\circ} 26^{\prime}\right.$, or $\left.1 \cdot 25\right)=36 \cdot 25$.

$32(2 \cdot 25+6 \cdot 25+9 \cdot 25+11 \cdot 25+12 \cdot 25)=82 \cdot 5$.

$42(2 \cdot 5+6 \cdot 5+9 \cdot 5+11 \cdot 5+12 \cdot 5)=85$.

${ }^{5} 2\left\{(2+1 \cdot 6+1 \cdot 2+0 \cdot 9+0 \cdot 6)\left(\operatorname{cosec}^{2} 45^{\circ}\right.\right.$, or 2$\left.)+2 \cdot 5\right\}=30 \cdot 2$. 


\section{Brought forward .. $115 \cdot 2$ units.}

The weight of the lower boom ${ }^{1}$ is proportional to . . . . 80.0 " and of the ties, ${ }^{2}$ to . . . . $32 \cdot 8$ ", the whole weight in tension, being therefore proportional to .

Hence the total theoretical weight of truss No. $2_{\mathrm{B}}$, is proportional to .

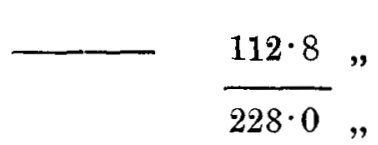

As in the case of No. 1, it will now be necessary to proportion the weight of the transverse stiffening required for the struts, deducing the weights for Nos. $2_{\mathrm{A}}$ and $2_{\mathrm{B}}$ from that actually put into No. 2.

The actual aggregate weight of the transverse stiffening, put into the 6 vertical struts of No. 2 , is $503 \mathrm{lbs} .{ }^{3}$, which is assumed to be the lightest possible. The theoretical weight of the same struts without joints or stiffening, is $976 \mathrm{lbs}$.; taking the intensity of the compressive stress at $3 \frac{1}{2}$ tons per square inch, this weight is proportional to 12.8 units. The weight of the stiffening is consequently proportional to 6.6 units, ${ }^{5}$ which is to be added to the weight of the truss, previously given.

Next as to No. $2_{\mathrm{A}}$; the two endmost struts $\mathrm{A} \mathrm{L}$ and $\mathrm{K} \mathrm{V}$ will be considered apart, as, like the end struts of No. 2, involving a different construction to the others. The sum of the vertical loads, as shown by the underlined figures upon the remaining eight struts, is 20 units, $^{6}$ which, multiplied by cosec. $63^{\circ} 26^{\prime}$ or $1 \cdot 118$ (the proportionate length), gives $22 \cdot 4$ as sum of pressures. The weight of stiffening in No. 2, being 503 lbs., and pressures 12.8 units, the stiffening in No. $2_{A}: 503:: 22 \cdot 4: 12 \cdot 8$ and would thus be 880 lbs. if the struts were the same proportionate length as in No. 2.

$2(2+6+9+11+12)=80$.

$22(2 \cdot 5+2+1 \cdot 6+1 \cdot 2+0 \cdot 9)\left(\right.$ cosec. $^{2} 45^{\circ}$, or 2$)=32 \cdot 8$.

3 Made up thus:-there are actually sixteen bracing-bars to each strut, about $2 \mathrm{ft} .3$ in. $\times 1 \frac{3}{4}$ in. $\times \frac{5}{\frac{5}{6}}$ in., each weighing 4 lbs.; to which must be added two pairs, or four bars, of the same weight, to replace the two plates to which the crossgirders are attached, which mode of fastening is inapplicable to Nos. $2_{A}$ and $2_{B}$. There is also to be added half the weight of the fuur short bars, or two pairs, at the top of each strut. Then $\left(4\right.$ lbs. $\left.\times 20+\frac{4 \times 1 \cdot 9 \mathrm{lbs}}{2}\right) 6=503 \mathrm{lbs}$.

- The aggregate number of units of stress to be supported by the six vertical struts is $(2 \cdot 8+2 \cdot 1+1 \cdot 5) 2=12 \cdot 8$. The unit being 10 tons, and the intensity 3.5 tons per sq. inch, the aggregate cross section is $\frac{12 \cdot 8 \times 10}{3 \cdot 5}=36.6$ sq. inches. The aggregate weight is therefore $366 \mathrm{lbs}$. per yard, and the mean length boing 22 yards, the total theoretical weight is $976 \mathrm{lbs}$., which is therefore proportional to $12 \cdot 8$ units of weight, the unit of stress and of weight being the same as before mentioned.

$5976: 12 \cdot 8:: 503: 6 \cdot 6$.

6 $2(3 \cdot 6+2 \cdot 8+2 \cdot 1+1 \cdot 5)=20$. 
But the length being to that in No. 2, as 1.118:1, the weight varies as $1 \cdot 118^{3}$ to 1 . Therefore the weight required $=880$ $\times 1.4=1232 \mathrm{lbs}$.; and as $503 \mathrm{lbs}$. is proportional to 6.6 units, so the proportionate weight of transverse stiffening required for No. $2_{A}$, is $16 \cdot 1$ units of weight, ${ }^{1}$ which is therefore to be added to the theoretical weight previously given.

As to No. $2_{B}$, the sum of the vertical loads carried by the 10 diagonal struts, as shown by the underlined figures, is 12.6 units, ${ }^{2}$ which, multiplied by cosec. $45^{\circ}$ or 1.414 (the proportionate length), gives 17.8 as the sum of pressures. The actual weight of stiffening in No. 2 being 503 lbs., and the pressures 12.8 units, the weight of stiffening in No. $2_{\mathrm{B}}: 503:: 17 \cdot 8: 12 \cdot 8$, and would thus be $700 \mathrm{lbs}$. if the struts were the same proportionate length as in No. 2. But the length being to that in No. 2 as 1.414 to 1 , the weight varies as $1.414^{3}$ to 1 ; hence the weight required $=700 \times 2.828=1979 \mathrm{lbs} . ;^{3}$ and as $503 \mathrm{lbs}$. is proportional to $6 \cdot 6$ units, so the proportionate weight of the transverse stiffening required for No. $2_{B}$, is 26 units of weight, ${ }^{4}$ which is therefore to be added to the theoretical weight previously given.

As in the trusses numbered 1 , so there are in the present cases several bars subject to compression, which it would be found impossible or inexpedient, to fine down to the small dimensions, proportional to the plain and underlined figures upon the diagrams.

In truss No. 2 (Plate 26), each of the vertical struts, consists of 4 angle-irons 3 in. $\times 3$ in. $\times \frac{3}{8}$ in. Smaller bars would not afford room for the necessary rivets required to carry out the condition of uniform stress; and for the same reasons it follows that smaller dimensions would be equally inadmissible ${ }^{5}$ in trusses No. $2_{\mathrm{A}}$ and No. $2_{\mathrm{B}}$.

The sectional area of the strut, the whole of which is available for compression, is 8.4 square inches ${ }^{6}$ the unit of stress (that is the load upon each joint of the truss), being 10 tons, and the intensity of the stress $3 \frac{1}{2}$ tons per square inch, this area corresponds to 2.94 units of stress, ${ }^{7}$ which multiplied by the sine of the obliquity

$1503: 6 \cdot 6:: 1232: 16 \cdot 1$.

$2(2+1 \cdot 6+1 \cdot 2+0 \cdot 9+0 \cdot 6)=12 \cdot 6$.

$31 \cdot 414^{3}=2 \cdot 828$.

$4503: 6 \cdot 6:: 1979: 26$.

5 It may be objected, that a lighter form of strat might be devised for Nos. $2_{\mathrm{A}}$ and $2_{B}$, because that peculiar form was dictated more by the nature of the crossgirder attachment than by its function as a strut; and that cross-girder attachment is inapplicable to $2_{\mathrm{A}}$ and $2_{\mathrm{B}}$, owing to their struts being inclined. But whatever form of strut and cross-girder attachment could be devised for those two trusses, the same could be adopted for No. 2, and therefore the results of the present comparison would not be materially affected.

6 Sectional area of one angle-iron $3 \times \frac{3}{8}=2.1$ sq. inches; $2 \cdot 1 \times 4=8.4 \mathrm{sq}$. inches.

$7 \frac{8.4 \times 3.5}{10}=2.94$ units. In explanation of the reason why the least practicable weight in units of the struts in No. 2 is greater than in No. 1, although the [struts 
gives the number marked by bracketted figures ${ }^{1}$ upon the diagrams, and must be considered as replacing, in all the three trusses, those underlined figures which are less than itself. The central vertical bar in No. 2, does not belong to the system of struts and ties; its use is to prevent the deflection of the top boom between $D$ and F, and as it is also constructed to receive the fastening of the middle cross girder, it is made of the same strength and stiffened in the same manner as the vertical struts, and its weight is consequently proportional to the number 4.04 written upon it in bracketted figures, which is made up of the before-mentioned 2.94 units, $+1 \cdot 1$ unit, the equivalent ${ }_{i}^{2}$ of its transverse stiffening.

The least practicable section for the inclined end struts, required to give sufficient lateral stiffness to the truss, was considered to be 21.48 square inches, made up thus, as shown by Fig. 5 .

Fig. 5.

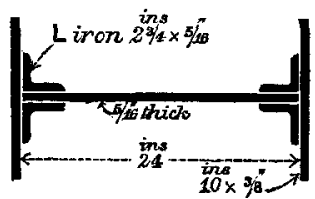

One transverse plate 24 in. wide $\times \frac{5}{16}$ ths thick, 4 angle-irons $2 \frac{3}{4}$ in. $\times 2 \frac{3}{4}$ in. $\times \frac{5}{16}$, in. and two side plates 10 in. wide $\times \frac{3}{8}$ in. thick, the total sectional area being $21.48 \mathrm{sq}$. in. At $3 \frac{1}{2}$ tons per square inch, this section is equivalent to 5.3 units of load, ${ }^{3}$ which number is accordingly marked in bracketted figures upon the diagram, and must replace the plain and underlined figures in the ultimate calculation.

For the reason just given the least practicable section for the end strut of No. $2_{A}$, would be the same as that used for No. 2 , namely

struts are shorter, it may be stated that the entire section, in the former case, is rendered available for resisting the compression, by reason of the peculiar mode of attachment to the ties and booms. (See page 411.) This mode of attachment could not well be applied with lighter angle-irons. As a set-off against this expenditure of material, less is required for stiffening, owing to the stiffness inherent in the shape of the augle-iron, and also to the circumstance that the line of action of the resultant of the compression intersects the centre of gravity of each angle-iron. Whereas, in No. 1, slightly more than half only of the section of the angle-irons is reckoned as available for compression, because the compression is not communicated directly by the rivets to the remainder, which, however, is accounted for in the calculations as part of the stiffening. See foot-note ${ }^{4}$, page 401.

1 Thus, in No. $2_{\mathrm{A}}, 2 \cdot 94 \times$ sin. $63^{\circ} 26^{\prime}$, or $0 \cdot 8944=2 \cdot 63$.

and in No. $2 \mathrm{~B}, 2 \cdot 94 \times$ sin. $45^{\circ}$, or $0 \cdot 7071=2 \cdot 1$.

2 The actual weight of this stiffening is $84 \mathrm{lbs}$;

then, as 503 lbs. : $6 \cdot 6$ units : : $84: 1 \cdot 1$.

$3 \frac{21 \cdot 48 \times 3 \cdot 5 \times \sin .45^{\circ} \text { or } 0 \cdot 707}{10 \text { tons per unit }}=5 \cdot 3$. 
21.48 square inches. This section is equivalent to 6.72 units $^{1}$ of vertical load, which number is accordingly marked in bracketted Fig. 6. figures upon the diagram No. $2_{\mathrm{A}}$. The

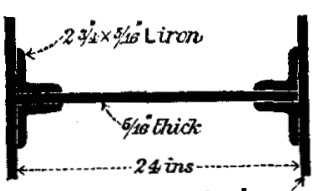
lightest bar $\mathrm{A} B$ of the top boom of this truss could not, it may be reasonably assumed, have a less section than $18 \cdot 18$ square inches, made up of one horizontal plate 24 in. $x$ $20^{\circ} \times x^{\circ}-1$. $\frac{5}{16}$ in., of which $21 \frac{1}{2}$ in. in width would be available in compression, four angleirons $2 \frac{3}{4}$ in. $\times \frac{5}{16}$ in. and 2 plates 10 in. $\times \frac{1}{4}$ in.

At $3 \frac{1}{2}$ tons per square inch, this section will resist a compression of 63.63 tons, equal to 6.36 units, which number is accordingly marked in bracketted figures upon the diagram. This number is also marked upon the lightest bar A B, of the top boom of truss No. $2_{B}$, as being proportional to the weight of the lightest section practicable in that case. In that truss the theoretical weight of the vertical pillar at the end is proportional to $2 \frac{1}{2}$ units of stress and weight, whereas the lightest pillar practicable to give the requisite stiffness and durability, would be equivalent to 6.65 units, ${ }^{2}$ which is the number marked in bracketted figures upon the diagram. The section would be that shown by the last figure, and would consist of one transverse plate 24 in. $\times \frac{5}{16}$ in., 4 angle-irons $2 \frac{3}{4}$ in. $\times \frac{5}{16}$ in., and two side plates 10 in. $\times \frac{1}{4}$, the total sectional area being 19 square inches.

The final comparison between the three trusses will now be as follows :-

Proportionate theoretical weight . . . . .

Proportionate weight of stiffening to struts.
Weight proportionate to the excess of practicable minimum over theoretical minimum, corresponding to the differences between the bracketted figures and the plain and underlined figures, superseded by them ${ }^{3}$

\begin{tabular}{|c|r|r} 
No. 2. & No, $2_{A} \cdot$ & No. $2_{\mathrm{Y}}$. \\
\hline $\begin{array}{r}\text { Units. } \\
237 \cdot 8 \\
6 \cdot 6\end{array}$ & $\begin{array}{r}\text { Units. } \\
237 \cdot 5 \\
16 \cdot 1\end{array}$ & $\begin{array}{r}\text { Units. } \\
228 \cdot 0 \\
26 \cdot 0\end{array}$ \\
$12 \cdot 08$ & $13 \cdot 42$ & $32 \cdot 82$ \\
\hline $256 \cdot 48$ & $267 \cdot 02$ & $286 \cdot 82$ \\
\hline
\end{tabular}

Proportionate total weight, exclusive of joints and) packings. . . . . . . . . . . .

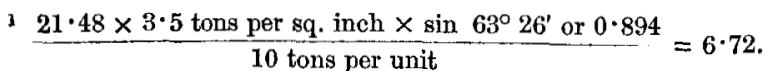

$2 \frac{19 \times 3.5 \text { tons per sq. inch }}{10 \text { tons per unit }}=6 \cdot 65$.

3 Thus as regards No. 2 :-

$$
\begin{gathered}
2\left\{(5 \cdot 3-4 \cdot 5) \operatorname{cosec}^{2} 45^{\circ}+2 \cdot 94-2 \cdot 8+2 \cdot 94-2 \cdot 1+2 \cdot 94-1 \cdot 5+\frac{4 \cdot 04}{2}\right\} \\
=2(1 \cdot 6+0 \cdot 14+0 \cdot 84+1 \cdot 44+2 \cdot 02)=12 \cdot 08 .
\end{gathered}
$$


It thus appears that No. 2 truss is lighter than either of its competitors, and that No. $2_{B}$ is much the heaviest of the three. 'The percentage in favour of No. 2, as compared with No. $2_{A}$, is $4 \cdot 15$ per cent., and, as compared with No. $2_{\mathrm{B}}, 11.87$ per cent.

From these comparisons it would appear that American engineers, who have extensively adopted the form of truss which is the type of Nos. 1 and 2, have in this matter displayed the usual acuteness of their nation, and deserved more credit than was awarded them in the discussion on Mr. Colburn's Paper ${ }^{1}$ two years ago.

\section{Section 3.-Peculiarities of Detail.}

The Author will now proceed to describe the peculiarities of detail in the two bridges, passing over, as not affecting the present subject, those features which resemble ordinary constructions of this kind.

Beginning with the method by which the load is transmitted from the cross girders to the main trusses, it is suggested that this has an important bearing upon the subject of uniform stress. It will be noticed that the trusses of both bridges have a double web, that is, the web is divided into two distinct halves, one on the inner side of the truss and one upon the outer side; and these two halves have no other connection with each other than is given by the light transverse stiffening bars, which are applied only to the struts, and to those ties which alternately act as struts, under the influence of the travelling load. This construction is of course perfectly well known, and is that usually applied in trusses of considerable span. In order that the stress may be uniformly distributed over the surface of any cross section of either boom, it is in the first place necessary that the two halves of the double web should each support, exactly, one half the load upon the truss. It is submitted that by the ordinary modes of fixing the cross girders this important condition cannot be realized; whether the cross girder rests upon the flat surface of the top boom, or is rivetted to the inner vertical side of a trough-shaped lower boom, or whether it is suspended from the latter by bolts or stirrup-irons applied to both sides of the lower boom, or, as is not so common, to one side only. In all these cases when the cross girder deflects,

As regards No. $2_{\mathrm{A}}$ :-

$$
\begin{gathered}
2\left\{6 \cdot 36-4 \cdot 5+(6 \cdot 72-4 \cdot 5+2 \cdot 63-2 \cdot 1+2 \cdot 63-1 \cdot 5) \text { cosec. }^{2} 63^{\circ} 26^{\prime}\right\} \\
=2\{1 \cdot 86+(2 \cdot 22+0 \cdot 53+1 \cdot 13) 1 \cdot 25\}=13 \cdot 42 .
\end{gathered}
$$

And as regards No. $2_{\mathrm{B}}$ :-

$$
\begin{gathered}
2\{6 \cdot 36-2 \cdot 5+6 \cdot 65-2 \cdot 5+(2 \cdot 1-2+2 \cdot 1-1 \cdot 6+2 \cdot 1-1 \cdot 2 \\
\left.+2 \cdot 1-0 \cdot 9+2 \cdot 1-0 \cdot 6) \text { cosec. }^{2} 45^{\circ}\right\} \\
=2\{3 \cdot 86+4 \cdot 15+(0 \cdot 1+0 \cdot 5+0 \cdot 9+1 \cdot 2+1 \cdot 5) 2\}=32 \cdot 82 . \\
\text { Vide Minutes of Proceedings Inst. C.E., vol. xxii. }
\end{gathered}
$$


whether the amount of deflection be appreciable or not, the entire load will be carried by the fastenings or supports upon the inner side of the truss, and consequently, by the inner half of the web, and the outer half, both of the web and of the booms, will be doing little more than resisting the stress caused by their own weight.

In the two bridges under consideration this effect is obviated and the condition of uniform stress realised, by supporting the cross girders in the middle of the width of the truss. In No. 1 bridge each cross girder rests upon a light cast-iron saddle or bridge, which spans the width of the top boom, and has its bearing partly upon the top edges of the vertical struts, and partly upon rivets passing through the struts and the vertical side-plates of the top boom. The cross girder has its bearing upon a raised fillet, cast upon the middle of the top side of the saddle, and shaped very slightly convex upwards (Plate 24, Figs. 1, and 5 to 12). In this way the line of action of the vertical force transmitted from the cross girder to the truss, coincides exactly with the vertical centre line of its width. The bottom edge of the saddle is raised sufficiently clear of the horizontal plate of the top boom to allow water to drain off from the centre of the span towards the ends of the truss, the camber of which affords sufficient inclination for that purpose.

In No. 2 bridge, as the roadway passes between the trusses near the bottom, a different arrangement was necessary. Each vertical strut consists of two pairs of vertical angle-irons, each 3 in. $\times 3$ in. $\times \frac{3}{8}$ in. thick, as shown in horizontal section in Plate 26 , the two of each pair being connected together by the transverse stiffening-bars, each $1 \frac{3}{4}$ in. $\times \frac{5}{16}$ in., crossing each other diagonally.

The two pairs of angle-irons are separated, in the plane of the truss, by a space just sufficiently wide to permit the end of the cross girder to pass in between the pairs. At the same level as the cross girder a plate, 12 in. deep $\times \frac{1}{2}$ in. thick, is rivetted to each pair of angle-irons; these two plates constitute a pair of small beams, which bridge over the width between the two angleirons of each pair; and in the centre of that width the end of the cross girder is rivetted to each plate by a cluster of eight rivets, placed as close together as possible. (Plate 26.) Thus the weight, transmitted by the cross girder to the truss, is equally divided between the four vertical angle-irons which constitute each vertical strut, and the resulting stress is thereby equally distributed between the two halves of the web, and, consequently, between the two halves of either boom. The same mode of attaching the cross girders is applied to the vertical ties, and to the central vertical bar, severally marked on the diagram of No. 2 truss 
(Plate 27), as A L, J T, and E P. A single-turned pin or bolt might perhaps have been substituted for each of the groups of rivets before mentioned with some advantage.

In both bridges the centre lines of the vertical struts, the diagonal ties, and the top and bottom booms, intersect each other at the centre of gravity of the group of rivets which attaches each strut and tie to the boom (Plate 24, Fig. 4); and, in order to satisfy the condition of uniform stress, it is necessary that these centre lines should intersect the centre of gravity of every cross section of each strut, tie, and boom; and in these two bridges this result is attained by making all the centre lines axes of symmetry. 'The struts in No. 1 bridge (Plate 24, Figs. 2 and 3) do not differ materially from a very common form of construction, each consisting of a pair of flat bars, each bar stiffened on the inner side by a pair of light angle-irons, between which the stiffening lattice-bars are rivetted. One side only of each of these angleirons, that lying in the plane of the truss, is reckoned as of pro ratâ value with the flat bars in resisting compression, the other limb of the angle-iron being considered only as stiffening, because it is only to the former that the stress is directly communicated by the rivetting. A A flat junction-plate (Plate 26) is rivetted to the top and bottom of each bar, wide enough and thick enough to receive the proper number of, and give sufficient bearing to, the rivets at the top and bottom joints. At the bottom of the strut this junction-plate is lengthened in the plane of the truss for a reason that will afterwards appear. With respect to No. 2 bridge, it has been already stated that each vertical strut consists of two pairs of vertical angle-irons; the two of each pair stiffened, in the plane at right angles to the plane of the truss, by a system of light diagonal bracing of flat bars. 'These four angle-irons are placed symmetrically with respect to the vertical centre-line of the strut, and they are connected (two and two) to the top and bottom joints by junction-plates of a proper size to receive the number of rivets required, and to give them sufficient bearing. These junction-plates are so contrived as to divide the stress, not only between the four angle-irons equally, but also equally between the two sides of each angle-iron, giving an equal amount of rivetbearing upon each side. Moreover, the centre lines of the rivets all intersect the centre of gravity of the cross section of each angle-iron. (Plate 26.)

The diagonal ties of the web are simple flat bars or plates. In No. 1 bridge the two marked E Q, Q G, diagram No. 1, are stiffened, transversely to the plane of the truss, by the same kind of lattice-work as is applied to the struts; because in those ties, as is well known, the greatest compression produced by the travelling load exceeds the tension produced by the fixed load. For 
the same reason in No. 2 bridge the four ties marked C O, D P, P F, Q G, are stiffened in a similar manner.

The condition of axial symmetry, by which the centres of gravity of the web-joints are made to coincide with the centres of gravity of the booms, is attained, in both bridges, by making the lower boom of two chains of plates, placed with their sides vertical. The plates constituting each chain are rivetted together, not only at the web-joints, but also continuously between them, in order to exclude the atmosphere from the inner surfaces, a mode of construction which has been often adopted. In the top booms of both bridges a section has been adopted which is believed to be new, and to present some peculiar advantages (Plate 24, Figs. 14 and 15). It is somewhat like a capital letter $\mathrm{H}$, elongated in the horizontal direction, or like a common plate-girder placed upon its side. The horizontal plate or diaphragm of the boom is no thicker than is necessary to give it sufficient lateral stiffness; each longitudinal edge of this horizontal plate is connected to one or more vertical plates by a pair of angle-irons, and the additional strength required towards the centre of the span is obtained by adding more of these vertical plates. The advantages of this kind of section are, that all its centre lines are axes of symmetry, and consequently intersect each other in its centre of gravity, and the horizontal axes are easily made to intersect the centres of gravity of the web joints. The chief mass of metal is also placed immediately contiguous to the bars of the web, which transfer the stress to the boom, instead of being at some distance from them, as in the trough-shaped and T-shaped form of boom. A collateral advantage is, that the material is disposed in the best possible manner for resisting vibration. This section has also a further advantage over the box-shaped section (which is otherwise a good one when made symmetrical) in giving complete facilities for examination and painting. The drainage of rain-water from the upper surface is effected by giving the truss considerable camber, which allows the water to flow out at the ends of the boom; and to prevent corrosion from this cause, the upper surface of the horizontal plate or diaphragm is coated smoothly with asphalte up to the level of the rivet-heads.

The ends of each truss rest upon hinged bearings, by means of cast-iron saddles rivetted to the junction of the endmost bars of the truss, rollers being provided at one end. (Plate 23.) This system of hinged bearings has been previously used in this country, but more frequently on the continent; and it is thought that there are good reasons to justify its universal adoption in all girders consisting of open framework, and even in plate girders of large span. 
The means adopted in the design of these girders, to obtain the utmost economy of weight consistently with moderate economy of workmanship were, the closest practicable approximation of the average strength to the minimum strength, the observance throughout of the condition of uniform stress, in order that all the compressed members might be trusted with the least possible weight of stiffening, the preference of rivetted web-joints to those formed by single pins, and such an arrangement of the rivetting, that every bar or plate subject to tension should have its whole width, less the diameter of only one rivet-hole, available to resist the tensile force applied to it. In order to carry out this last condition, at the points where the bars of the web join the lower boom, the junction-plates before spoken of as being applied to the lower ends of the struts are elongated so as to take up, rivet by rivet, part of the stress upon the boom before it arrives at the joint, and to give it out again in the same manner upon the opposite side of the joint. Thus the section along any line of rivets is sufficient to give, at the least, the minimum strength required.

The maximum limits of the tensile and compressive stress have been already stated. The strength of the rivetting is regulated by the condition that the pressure upon the rivet-bearing shall not exceed 5 tons per square inch, and that the intensity of the shearing stress upon the section of any rivet shall also not exceed the same limit.

It is now proposed to demonstrate, by comparison, the detrimental effect of unequally distributed stress.

\section{Section 4.-Comparison With a trough-shaped Boom.}

In order to illustrate the true value of the condition of uniform stress in its relation to the construction of girders, an exact comparison will now be attempted of the state of the bar D E, of the top boom of truss No. 2 (diagram No. 2), when under uniform stress, with that condition of unequally distributed stress, that would occur, if the boom had a suitable trough-shaped section of equal area, and therefore equal nominal value.

That this may be done in a complete and comprehensive nnanner, an exact demonstration will be given of what appears to be the best method of calculation, applicable to this object.

In Professor Rankine's admirable work on "Applied Mechanics," the effect and mode of action of unequally distributed stress are investigated; but the reasoning is so completely generalised (as indeed it should be in a work of that nature), in order to include all possible cases, that many of the steps are unavoidably complicated, and troublesome to follow. By confining the investigation to a specific practical instance, some of the considerations which 
complicate the' perfectly general 'solution will be eliminated, and a simplification, which it is hoped may be useful, will result.

It is therefore proposed to adapt this general method to the specific instance of a trough-shaped boom, of definite form and dimensions, and capable of comparison with the form of boom adopted for one of the trusses previously described.

Let Fig. 3, Plate 27, represent the section of a top boom, having the trough shape, the interior depth being the same as the extreme depth of the boom of No. 2 truss, and having the same sectional area. And let the figure A B CD, Fig. 4, represent in isometrical projection, the same trough-shaped cross section; the plane of section being at right angles to the longitudinal line, joining the centres of gravity of the top joints of the web of the truss, and situated at a sensibly small distance from the nearest of those joints. $A B$ is the top, and A D and BC the sides of the trough, C and D being its lower corners. Let $O$ be the centre of gravity of this plane of section; $-\mathrm{Y} \mathrm{O} \mathrm{Y,-X} \mathrm{OX,} \mathrm{a} \mathrm{pair} \mathrm{of} \mathrm{rectangular} \mathrm{axes} \mathrm{of}$ co-ordinates traversing $O$, as origin, in the plane of section, and parallel, respectively, to $\mathrm{AB}$ and $\mathrm{CB}$; and, $-\mathrm{Z} O \mathrm{Z}$, an axis perpendicular to that plane.

\section{Case 1.-STRess UnfFolm in Intensity.}

It is necessary, in the first place, to exhibit an exact solution of this case, because some of the mathematical expressions involved in it, are also involved in the solution of the case of stress unequally distributed, to be afterwards considered.

Let it be supposed, then, that the centres of gravity of the several joints, which connect the bars of the web with the top boom, lie in the axis $-Z O Z$, supposed for that purpose to be indefinitely continued. It is evident that the stress upon the plane of section, is entirely produced by the forces applied to the top boom by the diagonal bars of the web, being the sum of the horizontal components of the diagonal stresses upon those bars, whose top joints lie between the plane and the nearest end of the truss. Then because the centre of gravity of each of those applied forces lies in the axis $\mathrm{O} Z$, the direction of the stress upon the plane of section must be wholly normal, and its resultant act in the direction of $\mathrm{O} \mathrm{Z}$, cutting the plane in its centre of gravity. It is therefore the resultant of a system of equal parallel forces, distributed uniformly over the surface of section; and $O$, the centre of gravity of the surface, coincides with the "centre of stress," or the "centre of pressure," as defined in section 1 .

So far as concerns the stress upon the surface A B C D, the trough will then be in a condition similar to that of a vertical pillar of the same figure of cross section, compressed in the direction of 
its vertical axis of gravityl $\mathrm{O} Z$, by a load which is correctly represented by the weight of an imaginary parallel-ended prismatic solid, A C F E, whose base coincides with the surface of section, and whose uniform height, $\mathrm{C} \mathrm{F}$, is proportional to the intensity of that load. The direction of the applied force being supposed downwards or negative, that of the stress which resists it is upward and therefore positive.

Let $\mathbf{P}=$ the amount, or magnitude, of the resultant of the stress.

$p_{0}=$ its intensity per square unit of the surface of section,

$\mathrm{V}=$ the volume of the solid A F,

$w=$ its weight per unit of volume,

$\mathrm{S}=$ the area in square units of the surface $\mathrm{A} \mathrm{BCD}$.

Then from the preceding argument, $\mathrm{P}=w \cdot \mathrm{V}=p_{0} \cdot \mathrm{S} ; p_{o}$ being a constant quantity, because the height $\mathrm{CF}$, of the solid is uniform.

Hence the preceding is a case of uniform stress, and requires no further remark, except this important one,- - that in order to produce this condition of the stress, it is necessary not only that the centre of gravity of each web joint shall lie in the plane $Z \mathrm{OY}$, but also in $Z \mathrm{OX}$. To effect this result, it is absolutely necessary that some such method of attaching the cross girders, be adopted as has been described in section 3. 'The details of such an attachment would not necessarily be the same as there described. It is obvious that many variations of detail are admissible in different circumstances; but it is essential that the effect shall be, to divide the load equally between the two lateral divisions of the web.

\section{Case 2.-Stress unequally Distributed.}

It is now proposed to investigate that condition, of unequal distribution of the stress, upon the plane of section, A B CD, of the trough, which is produced, when, as is generally the case in practice, the longitudinal line joining the centres of gravity.of the web joints, traverses the plane of section at a point $R$, whose perpendicular distance below $\mathrm{OY}$ is $\mathrm{OR}$; $\mathrm{R}$ being thus the "centre of stress" as defined in section 1 . As the solution is much simplified, by supposing the point $R$, to lie somewhere in the axis - $\mathrm{XOX}$, and as the result will then be that most favourable to the cause of the trough-shaped boom, it will be assumed that some mode of attaching the cross girders is adopted, equivalent to that just alluded to, which will effect that object. Supposing the amount of the diagonal forces acting through the bars of the web, and also the area $S$, of

1 "Axis of gravity," a short phrase signifying the line intersecting the centres of gravity of every plane cross section of the boom, or pillar. 
the plane of section to remain the same as in case 1 , the magnitude $P$, of the resultant of the stress upon that plane, will remain the same as in that case. The direction of the resultant, and also of all the parallel components, of the stress upon the plane will remain the same, that is to say, normal to the plane, its position being close to one of the web joints, and it being assumed ${ }^{1}$ that no sensible flexure of the boom can at that point take place, which would affect the direction of the stress with respect to the surface of section.

Having fixed the preceding data, it will now be evident that the trough is in a similar condition to that of a vertical pillar compressed by a load $-\mathrm{P}$, which will be correctly represented by the weight of an imaginary prismatic solid. A B C D S T G, (Fig. 4, Plate 27), whose base coincides with the surface of section, and whose specific gravity and volume are the same as in case 1 ; but whose perpendicular height $z$, at any point in the surface of section, varies in proportion to the intensity of the stress at that point. The essential object of the present investigation is to find a method of calculating the relative values of $z$, and particularly its greatest and least values.

For the sake of brevity, the parallel ended solid, A C F E, will be called No. 1 solid, as belonging especially to case 1 ; and the new solid A BC D H S G ' $\Gamma$, will be distinguished as solid No. 2. It must be distinctly remembered, that the weights, and consequently the volumes of the two solids, are exactly equal; and as they stand upon the same base, the difference between them is only in height ; C F, that of No. 1, being uniform, and the height of No. 2 varying from $B \mathrm{~T}$ to $\mathrm{CH}$, according to a law depending upon the distance $O R$, and upon the perfection, or imperfection, of the elasticity of the material subjected to the action of the stress. As is usual in all similar investigations, it is assumed that Hooke's law of perfect elasticity is sensibly true for wrought iron, ${ }^{2}$ the material generally employed in structures of this kind.

The centre of gravity of solid No. 2, will necessarily lie somewhere in the line, $R R^{\prime}$, drawn parallel to $O Z ; R R^{\prime}$ is therefore the line of action of the resultant, $-P$, of the set of parallel forces

1 This assumption may possibly be questioned in the case of a plane of section so near the centre of the span of the girder. But whether true or not in such a case, it is undoubtedly true when the plane of section is situated near to one of the endmost joints ; for instance, the joint $A$ in the bay $\mathbf{A} B$. And if the ratio $\frac{P}{S}$ be not less in that instance than in the former (as it manifestly should not be), then the detriment to the strength of the structure will be as great as if the assumption in the text were unquestionably true. Generally the detrimental effect will be proportionate to the absolute value of that ratio, other things being equal.

2 See note', page 421 . 
acting vertically (the boom being considered as if it were a vertical pillar), which compose the weight of No. 2 solid. ${ }^{1}$

As the magnitude, $\mathrm{P}$, of the total stress is the same as in case 1 , its mean intensity to be denoted by $p_{0}$, in the present case will be the same as the uniform intensity in case 1 . Consequently there will be a line in the surface of section A B C D, for which the ordinate, $z$, of No. 2 solid, will $=\mathrm{C} \mathrm{F}$, the height of solid No. 1. This being so, the entire stress upon the section may be considered as made up of two parts, viz. :-

First, a uniform stress, whose intensity is the mean intensity of the entire stress, and whose centre is the centre of gravity, $O$, of the surface of section A B C D. As in case 1, this mean intensity is $p_{0}=\frac{\mathrm{P}}{\mathrm{S}}=\frac{\text { total stress }}{\text { area }}$. Secondly, a varying stress, whose amount is nothing, and which is therefore positive and negative (or compressive and tensile), on the opposite sides of some neutral axis traversing the plane of section. 'The intensity, $p^{\prime}$, of this second part of the stress, at any point in the surface, is the deviation of the total intensity at that point from the mean; so that the total intensity at any given point, is expressed by the equation $p=p_{0}+p^{\prime}$.

On the assumption that Hooke's law is sensibly true, the varying stress just spoken of, is " an uniformly varying stress ;" that is, a stress whose intensity, at a given point of the surface to which it is applied, is proportional to the distance of that point from the neutral axis which will be proved to traverse the centre of gravity, $O$, of the surface of action.

This composition of the entire stress is represented in the diagram, Fig. 4, Plate 27, by the solid No. 2, being considered as made up of-the parallel ended solid No. 1, shown in outlines, representing the uniform stress $P$, plus the shaded wedge-shaped solids, $\mathrm{F} \mathrm{H} k$, and $\mathrm{N}$ S $n$, and minus the shaded wedge-shaped solid $k n$ J T E G, which together represent the uniformly varying stress whose amount is nothing. ${ }^{2}$

As the first part of the stress, represented by the solid No. 1, has been already determined, it now remains to find the resultant of the second part of the stress ; the value and effect of this resultant depending upon the volume and figure of the shaded double wedgedshaped solid, N S F H E T. The shortest method of solving this part of the problem, is by the process of integration.

In the plane $\mathrm{EJ} \mathrm{F} \mathrm{N}$, assume a new pair of rectangular axes, - $Y^{\prime} O^{\prime} Y^{\prime},-X^{\prime} O^{\prime} X^{\prime}$, parallel to, and in the same vertical

1 Because $\mathbf{R} \mathbf{R}^{\prime}$ coincides with the line of action of the resultant of the applied forces brought on to the plane of section by the pull upon the diagonal bars of the web.

2 It should be observed that $-\mathrm{P}$ is the weight of the solid acting in a downward direction, while $+\mathbf{P}$ is the equal and opposite stress acting upward. 
planes as the original axes. It is evident, that the moments of any element, of the second part of the stress, with respect to the new axes, will give precisely the same result, as affectirig the surface of section, as if reckoned with respect to the original axes. The object of the change of axes, being merely, to make the geometrical representation by means of the diagram, consistent with the algebraic symbols employed.

Consider the surface $\mathrm{E} \mathrm{J} \mathrm{F} \mathrm{N}$, whose area is $\mathrm{S}$ (being the same as A B C D), to be composed of an infinite number of infinitesimally small rectangular elements, the area of each being denoted by the differential $d x d y$, and the stress upon each by $p^{\circ} d x d y$.

Let the axis of co-ordinates $-\mathrm{Y}^{\prime} \mathrm{O}^{\prime} \mathrm{Y}^{\prime}$ be for the present assumed (as will afterwards be proved) to be the neutral axis of the stress; $x$ is then the perpendicular distance of any one element from this neutral axis. By the definition of "a uniformly varying stress," previously quoted, the equation $p^{\prime}=a x$, or $a=\frac{p^{\prime}}{x}$ ( $a$ being a constant), represents the law of variation of the uniformly varying stress. ${ }^{1}$ Then, because the ratio $a$ is constant, the inclined surface, HST G, is a plane surface; and the ordinate, $z$, proceeding from any element of the plane surface, E J F N, to that inclined plane, will be proportional to the intensity, $p^{\prime}$, of the stress upon that element, and will indicate, by its upward or downward direction, whether that stress is positive or negative; and the nullity of the whole varying stress will be indicated by the equality of the volumes of the positive wedges $\mathrm{FH} k, \mathrm{NS} n$, to that of the negative wedge $k n J \mathrm{JEG}$. Then, because the amount of the stress upon the plane $\mathrm{EJ} \mathrm{F} \mathrm{N}$ is nothing, its resultant is a couple whose moment to be denoted by $\mathbf{M}$, and the position of its axis, which must necessarily ${ }^{2}$ be the neutral axis of the total stress, is to be found as follows:- $w$, as before being the uniform weight per unit of volume of the solids, the stress acting upon each rectangular element is

$$
w z \cdot d x d y=p^{\prime} d x d y=a \cdot x d x d y
$$

because $p^{\prime}=a x$. The moment of that stress round $\mathrm{O}^{\prime} \mathrm{Y}^{\prime}$ is

$$
x w z^{*} d x d y=a x^{2} d x d y \text {, }
$$

and is right-handed or positive, looking from $+\mathrm{Y}^{\prime}$ towards $\mathrm{O}^{\prime}$, and round $\mathrm{O}^{\prime} \mathrm{X}^{\prime}$ is

$$
y w z \cdot d x d y=a \cdot x y d x d y \text {, }
$$

1 This law requires the ratio $p^{\prime}: x$ to be a constant ratio; whereas, if the variable stress was not uniformly varying, $a$ would not be constant; $a$ is therefore the intensity, per unit of area, of the stress at the distance unity from the neutral axis.

2 "Necessarily," because the first part of the stress being of uniform intensity, and having, therefore, no neutral axis, the neutral axis of the second part of the stress, that is, the axis of the couple, must be the neutral axis of the whole stress. 
which is right or left-handed, looking from $+\mathrm{X}^{\prime}$ towards $\mathrm{O}^{\prime}$, according as the element is situated on one or the other side of - $\mathrm{X}^{\prime} \mathrm{O}^{\prime} \mathrm{X}^{\prime}$. Summing and integrating these elementary moments, the total moments of the partial resultant couples are found,

$$
\begin{aligned}
& \text { round } \mathrm{O}^{\prime} \mathrm{Y}^{\prime} \text { to be } \mathrm{M}_{y}=a \cdot \iint x^{2} d x d y, \\
& \text { round } \mathrm{O}^{\prime} \mathrm{X}^{\prime} \text { to be } \mathrm{M}_{x}=a \cdot \iint x y d x d y .
\end{aligned}
$$

Then, as is well known, the moment of the resultant couple will be

$$
\mathbf{M}=\sqrt{ }\left(\mathbf{M}_{x}^{2}+\mathbf{M}_{v}^{2}\right) \text {. }
$$

But because the figure $\mathbf{E ~ J ~ F ~ N , ~ t h a t ~ i s , ~ t h e ~ s e c t i o n ~ o f ~ t h e ~ t r o u g h , ~}$ is symmetrical round the axis $-\mathrm{X}^{\prime} \mathrm{O}^{\prime} \mathrm{X}^{\prime}$, which contains the point $\mathrm{R}^{\prime}$, then for every point at which $y$ has a given positive value there is a corresponding point for which it has an equal negative value; so that in the present case, the integral

$$
\iint x y \cdot d x d y=0 \text {. }
$$

Hence $\mathbf{M}_{x}$ vanishes, and the moment of the resultant couple is simply

$$
\mathbf{M}=a \cdot \iint x^{2} \cdot d x d y=a \mathrm{I},
$$

which is, in fact, merely the constant, $a$, multiplied into the wellknown expression for the moment of inertia of the surface $E J F N$, that is, A B C D, taken with respect to the assumed neutral axis $\mathrm{O}^{\prime} \mathrm{Y}^{\prime}$. It now remains to prove the truth of that assumption thus. The partial resultant couples relative to the rectangular axes being respectively $\mathbf{M}_{x}$ and $\mathbf{M}_{y}$, it is well known that the angle $\theta$ which the axis of the resultant couple makes with $O^{\prime} \mathrm{X}^{\prime}$ is to be found by the equation

$$
\cos \theta=\frac{\mathbf{M}_{x}}{\mathbf{M}} \text {. }
$$

In the present case $M_{x}$ vanishes, therefore $\cos \theta$ vanishes, $\theta$ is a right angle, and hence the axis of the couple coincides with - $\mathrm{Y}^{\prime} \mathrm{O}^{\prime} \mathrm{Y}^{\prime}$, which must also traverse the centre of gravity of the section for the following reason. The resultant of the second part of the stress being a couple, the magnitude of the stress is nothing, and is expressed by

$$
\iint p^{\prime} d x d y=0
$$

but because $p^{\prime}=a x$, in which $a$ is constant and $x$ variable,

$$
\iint p^{\prime} d x d y=a \cdot \iint \begin{aligned}
& x d x d y=0, \\
& \text { and therefore } \iint x d x d y=0 .
\end{aligned}
$$

Let $x_{0}$ be the co-ordinate, relative to $-\mathrm{Y}^{\prime} \mathrm{O}^{\prime} \mathrm{Y}^{\prime}$, of the centre of gravity of the surface; then the well-known general equation of $x_{0}$, for the centre of gravity of any plane surface, relative to any rectangular axis of $y$, gives

[1864-65. N.s.]

$$
x_{0}=\frac{\iint x d x d y}{\iint d x d y}
$$


But $\iint d x d y$ is the area of the surface, and has the magnitude $\mathrm{S}$; therefore $x_{0}$ must be nothing, and hence the neutral axis, $-\mathrm{Y}^{\prime} \mathrm{O}^{\prime} \mathrm{Y}^{\prime}$, must traverse the centre of gravity of the surface E J F N, as was previously assumed. ${ }^{1}$

It is thus proved that the total stress upon the original plane, A B C D, is resolved into a force, $P$, which is the magnitude of the entire stress upon that plane, applied at its centre of gravity $O$, and acting in the direction $\mathrm{OZ}$, + a right-handed ${ }^{2}$ couple, whose moment is $\mathrm{M}=a \mathrm{I}$, whose tendency is to turn the plane, E J F N, round the axis $O^{\prime} Y^{\prime}$, elevating the edges, $F$, and depressing the opposite edge, $\mathrm{E} J$, until they coincide respectively with $\mathrm{H} \mathrm{S}$ and G T. As is well known, the effect of such a combination of a single force with a right-handed couple, is to shift the line of action of the resultant, $P$, parallel to itself, in a direction perpendicular to the neutral axis, $\mathrm{OY}$, and to the left of $\mathrm{O}$ (looking from $+\mathrm{Y}$ towards $\mathrm{O}$ ), through a distance

$$
\mathrm{L}=\frac{\mathrm{M}}{\overline{\mathrm{P}}}=\frac{a \mathrm{I}}{\mathrm{P}} ;
$$

$\mathrm{L}$ being thus the arm of the couple $\mathrm{M}$, and equal to $\mathrm{O} R$, the perpendicular distance of the line of action of the resultant of the applied force, $-\mathbf{P}$ (which alone produces the stress, and is equal and opposite to $\mathbf{P}$ ), from the neutral axis - $\mathrm{Y} \mathrm{O} \mathrm{Y}$.

Substituting, in the last equation, for the constant $a$ its value as previously determined, the equation

$$
\frac{p}{x}^{\prime} \mathrm{I}=\mathrm{LP}
$$

is deduced, which is an equation of moments from which may be computed the intensity $p^{\prime}$ of the second part of the stress at any point whose perpendicular distance from $\mathrm{OY}$ is $x$. That is to say,

$$
p^{\prime}=\frac{x \mathrm{~L} \mathrm{P}}{\mathrm{I}},
$$

which being added to $p_{0}$, the uniform intensity of the first part of the stress, that is, the mean intensity, $\frac{P}{S}$, gives the total intensity of the stress at that point, observing, of course, the positive or negative signs of $p^{\prime}$ and $x, p_{0}$ being considered positive.

1 If $\mathrm{R}$, instead of being situated in the plane $\mathrm{ZOX}$, had been situated at any distance to one side or the other of that plane, the neutral axis of the stress would still intersect $O^{\prime}$, the centre of gravity of the surface, and would make an angle $\theta$ with $-\mathrm{X}^{\prime} \mathrm{O}^{\prime} \mathrm{X}^{\prime}$ to be determined by the equation $\cos \theta=\frac{M_{x}}{\bar{M}^{-}}, M_{x}$ in such a case having a value to be obtained by solving the equation for $\mathbf{M}_{x}$ given in the text.- See Rankine's "Applied Mechanics," arts. 91 to 95.)

2 "Right-handed," when it is viewed by an observer, looking from $+\mathbf{Y}$ towards $O$, his head being in the direction of $+z$. 
This final result is denoted by the equation

$$
p=p^{\circ} \pm \frac{x \mathrm{~L} \mathrm{P}}{\mathrm{I}} \text {. }
$$

Applying this formula to the case of the trough-shaped section of boom, shown in Fig. 3, Plate 27, which is a section supposed to be equivalent to the $\mathrm{H}$-shaped section actually used for the division $\mathrm{DE}$ of the top boom of truss No. 2, the following results are obtained. The trough is supposed to have the following dimensions : the top plate is $\frac{5}{8}$ in. thick and about $2 \mathrm{ft} .2 \frac{1}{8}$ in. wide, connected by two angle-irons $2 \frac{3}{4}$ in. $\times 2 \frac{3}{4}$ in. $\times \frac{5}{8}$ in. to the two sides, supposed each to be 10 in. wide $\times 1 \frac{1}{6}$ in. thick. It is submitted that this arrangement of the material is not unfavourable to the cause of the trough-shaped section, because there are many actual instances where the sectional area of the top bears a greater proportion to that of the vertical sides than in this example. The area of section is $36 \cdot 17$ square inches, exactly equal to that in No. 2 truss. The inside depth of the trough being 10 inches, will permit exactly the same disposition of the rivets in the web-joint; so that the centre of pressure, $R$, is situated at the same perpendicular distance, viz., 5 inches, from the lower edges of the trough as from the lower edges of the $\mathrm{H}$-shaped section actually used. The centre of gravity, $\mathrm{O}$, is found to be situated at 8.088 inches perpendicular distance from the lower edge of the trough, and 2.537 inches from the top edge, L being therefore $3 \cdot 088$ inches. The magnitude of the total stress upon the section is $P=125$ tons. The uniform intensity of this stress is $p_{0}=3.45$ tons per square inch, and the moment of inertia with respect to the axis, $\mathrm{OY}$, is $\mathrm{I}=336 \cdot 902$. The extreme values of $x$ are

$$
-x=8.088 \text { inches, and } x=2.537 \text { inches. }
$$

From these data the greatest stress is found to be at the edges $\mathrm{C}$ and $\mathrm{D}$, and

$$
=p=12 \cdot 717 \text { tons per square inch, }
$$

the least intensity occurring at the edge $\mathrm{A} \mathrm{B}$, and being

$$
=p=0.544 \text { tons per square inch. }{ }^{1}
$$

1 The numerical details of this calculation are given at length in the Appendix. Comparing the proportions of the trough-shaped section in Fig. 3, Plate 27, with those of many existing instances, it would appear that the inequality and greatest intensity of the stress calculated by the formula, on the supposition of perfect elasticity, must in existing bridges often exceed that attributed to the example. Therefore the question naturally arises, Why are not frequent break-downs or, at all events, serious crippling, heard of as arising from this cause? In reply to this question, the Author wishes to suggest, that possibly the imperfect elasticity of the material, which is very properly considered to be a defeet, is, in fact, the salvation of those structures. 'This suggestion may be illustrated by reference to the diagram Fig. 4, Plate 27, in this way. When the material at the erge, $\mathrm{O}$ and $\mathrm{D}$, suffers by 
Anything like this enormous inequality in the stress, shown to exist in such examples as the preceding, ought not to be permitted, and it is submitted that this subject, minute and highly refined as it appears to be, is worthy of attentive consideration; and the Author hopes that a full discussion and criticism of the preceding argument will eliminate whatever errors it may contain, and will result in the further establishment, upon a firmer and wider basis, of sound principles in this department of construction.

In summing up the conclusions which the Author has sought to establish, he submits that-

First, A comparatively small deviation of the centre of stress upon the cross section of any bar, of any piece of framework, from the centre of gravity of that section, produces, within the limits of elasticity, a comparatively great inequality in the distribution of the stress upon that section.

Secondly, If it be conceded that tine real strength of every structure is inversely proportional to the greatest strain suffered by its

the application of the test-load, a strain exceding the limit of elasticity (which occurs when the strain exceeds about 11 or 12 tons per square inch), it takes a permanent set, which remains after the load is removed. The effect of this permanent set is known to be, ${ }^{*}$ that a reapplication of the load producing the same stress would produce a less proportionate strain, or alteration of figure, than at first; so that Hooke's law, which states that the strain is proportional to the stress, would no longer apply. The oblique plane surface $\mathbf{H ~ S ~ G ~ T , ~ w h o s e ~ i n c l i n a t i o n ~ r e p r e s e n t s ~}$ to the eye the action of that law, would, at the point whose $z$ co-ordinate, measured by the scale, represents the limit of elasticity, cease to be plane, and would become curved and concave downward as it approaches $H S$, thereby shortening the ordinate $\mathrm{FH}$ or N S, and consequently diminishing the volume of the positive wedgeshaped solids $H \mathrm{~F} k$ and $\mathbf{S} N n$. But in order to maintain the equality of volume of the positive and negative wedges, which is necessary, to make the resultant of the second part of the stress nothing, an equal diminution in the volume of the wedge $\mathbf{G} \mathbf{E} \mathbf{J} \mathbf{T} k n$ would ensue. But because the intensity of the stress on that part of the section lying between the neutral axis and the edge $A B$ is far within the limit of elasticity, the oblique surface between $k n$ and $\mathrm{T} \mathrm{G}$ must remain a plane surface, and therefore the diminution in the volume of the negative wedge would necessarily involve a shifting of the neutral axis out of the centre of gravity, and towards $R$, together with a shortening of the negative ordinates $J \mathbf{T}$ and $\mathbf{E} G$. The immediate effect of this would be a redistribution of the stress upon the plane of section, increasing its intensity at the edge $\mathbf{A} \mathbf{B}$, and diminishing it at $\mathbf{C} \mathbf{D}$. In the preceding remarks the author must not be understood as even suggesting that the elastic limit may be safely exceeded either in iron or any other material. He merely suggests that, in the precise kind of case selected for illustration, the permanent set produced, at one edge only, by such excess, caused by the proof load, occasions a shifting of the neutral axis, and a consequent redistribution of the stress due to the reapplication of a load less than the proof load.

There is no doubt that the formula in the text gives correct results, under the assigned conditions, up to a maximum limit of stress, whether tension or compression, of 11 or 12 tons per square inch; but to give correct results beyond that limit, the formula would require the introduction of a term expressing the law of variation of the proportion between the strain and the stress, when the latter exceeds that limit. The value of such a term can only be deduced from a carefullyperformed set of experiments, specially directed to that object.

*Vide Fairbairn's "Useful Information for Engineers." Second Serles, p. 125, where details are given of some experimenis at Woolwich, whose results support this view. 
weakest member, then the existence of this unequal distribution of the stress must be detrimental to the strength of any structure in which it exists, and which has been designed on the supposition that the mean intensity of the stress upon any bar is necessarily a correct measure of its strength.

Thirdly, There is no practical or theoretical difficulty, in designing a truss or girder, in which the stress upon every cross section, of all the important members at all events, shall be absolutely uniform.

Fourthly, The condition of uniform stress is perfectly consistent with the utmost economy of material in the structure to which it is applied.

The Paper is illustrated by numerous drawings and diagrams, from which Plates 23, 24, 25, 26, and 27, and woodcuts, Figs. 1 to 8 , have been compiled. 


\section{A P P E N D I X.}

Applicstion of the formula, $p=p_{\circ} \pm \frac{x \mathrm{~L} \mathrm{P}}{\mathrm{I}}$, to find the greatest and least values of $p$ on the section, Figs. 7 and 8 , where the line of action of the resultant intersects the plane of section at a point, $R$, whose perpendicular distance below the horizontal axis - Y O Y intersecting the centre of gravity, $O$, of the surface, is $L$, the point $R$ lying in the vertical axis - XOX.

Fig. 7 .

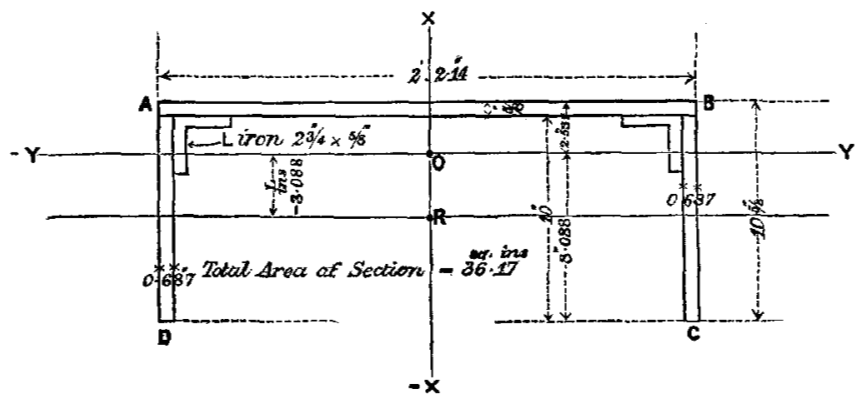

Section of Trough.

Fig. 8.

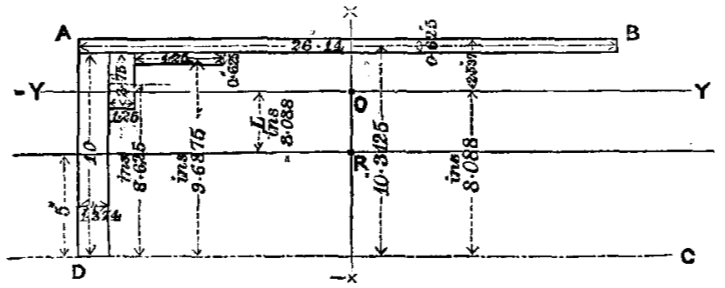

Equivalent Section arranged in the form most convenient for the calculation.

To find height of - Y Y above lower edge CD; that is, to find position of neutral axis of section.

Inches. Inches. Sq. Ins.

No. 1. Area rect. $10 \times 1 \cdot 374=13 \cdot 74$, moment $=13 \cdot 74 \times 5 \quad$ sq. $68 \cdot 70$

No. 2. " " $2.75 \times 1.25=3.44, "=3.44 \times 8.625=29 \cdot 67$

No. 3. " " " $" 4.25 \times \cdot 625=2 \cdot 65, \quad "=2 \cdot 65 \times 9 \cdot 6875=25 \cdot 67$

No. 4. " " $" 26 \cdot 14 \times .625=16 \cdot 34, \quad " \quad=16 \cdot 34 \times 10 \cdot 3125=168.50$

Sum of areas $=\overline{36 \cdot 17} \quad$ Sum of moments $\overline{292 \cdot 54}$

Then $\frac{292 \cdot 54}{36 \cdot 17}=8 \cdot 088$ inches $=$ height of - Y O Y above C D.

Hence $L=8 \cdot 08-5=3 \cdot 088$ inches. 
Computation of I with respect to - Y O Y.

Dimensions of each rectangle are, parallel to $x$, side $=h$, parallel to $y$, side $=c$; distance of its centre from $O Y=x_{\circ}$.

Then $\mathrm{I}=\mathrm{\Sigma} \cdot \frac{h^{3} c}{12}+\mathrm{\Sigma} \cdot h c x_{\mathrm{o}}^{2}$.

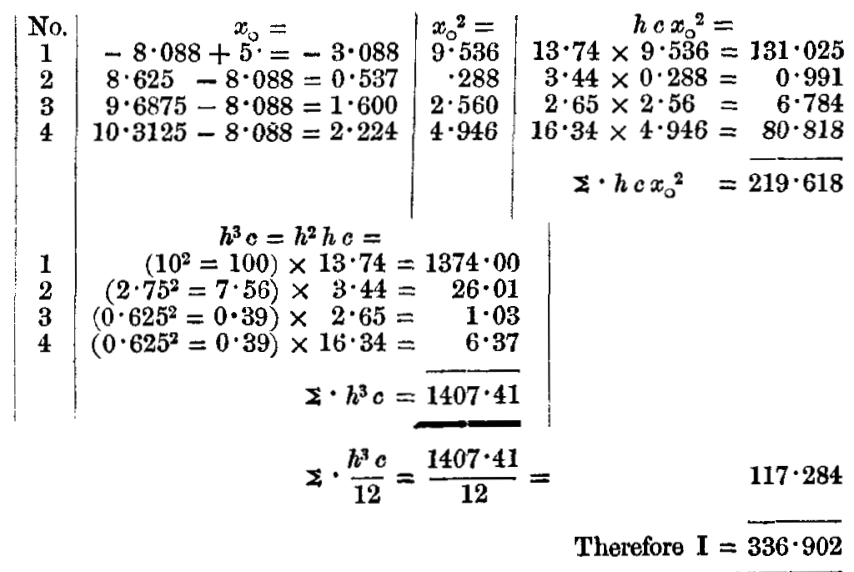

The extreme values of $x$ are,

$$
\begin{aligned}
-x & =-8.088 \text { inches, } \quad x=2.537 \text { inches, } \\
\mathbf{L} & =-3.088 \quad, \\
\mathbf{P} & =125 \text { tons; } \\
\cdot \quad p^{\prime} & =\frac{-x(-\mathrm{L}) \mathrm{P}}{\mathrm{I}} \\
& =\frac{-8.088 \times-3.088 \times 125}{336.902}=9.267 \text { tons per sq. inch, } \\
\text { and }-p^{\prime} & =\frac{x(-\mathrm{L}) \mathrm{P}}{\mathrm{I}} \\
& =\frac{2 \cdot 537 \times-3.088 \times 125}{336.902}=-2.906 \quad, \quad ", \quad, ",
\end{aligned}
$$

Therefore, at the edges $C$ and $D$ of the trough,

and at the edge $\mathbf{A B}, \quad \begin{aligned} & p=p_{\circ}+p^{\prime}=3 \cdot 45+9 \cdot 267 \\ & p=p_{\circ}-p^{r}=3 \cdot 45-2 \cdot 906\end{aligned}$

$$
p=p_{\circ}+p^{\prime}=3 \cdot 45+9 \cdot 267=12 \cdot 717 \quad \text {, " , }
$$

$$
=0.544 \text { tons per sq. inch. }
$$


篦

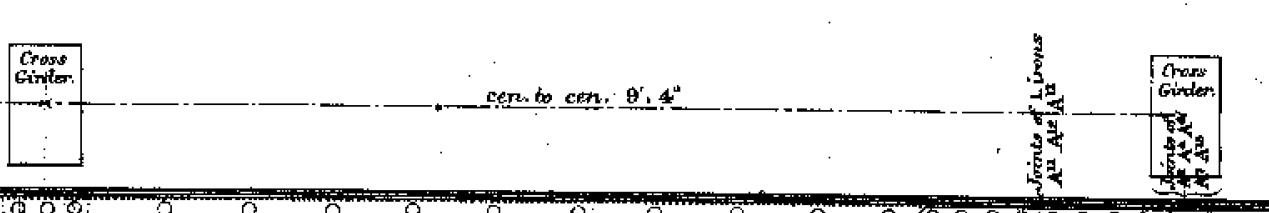

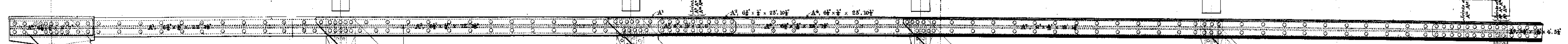
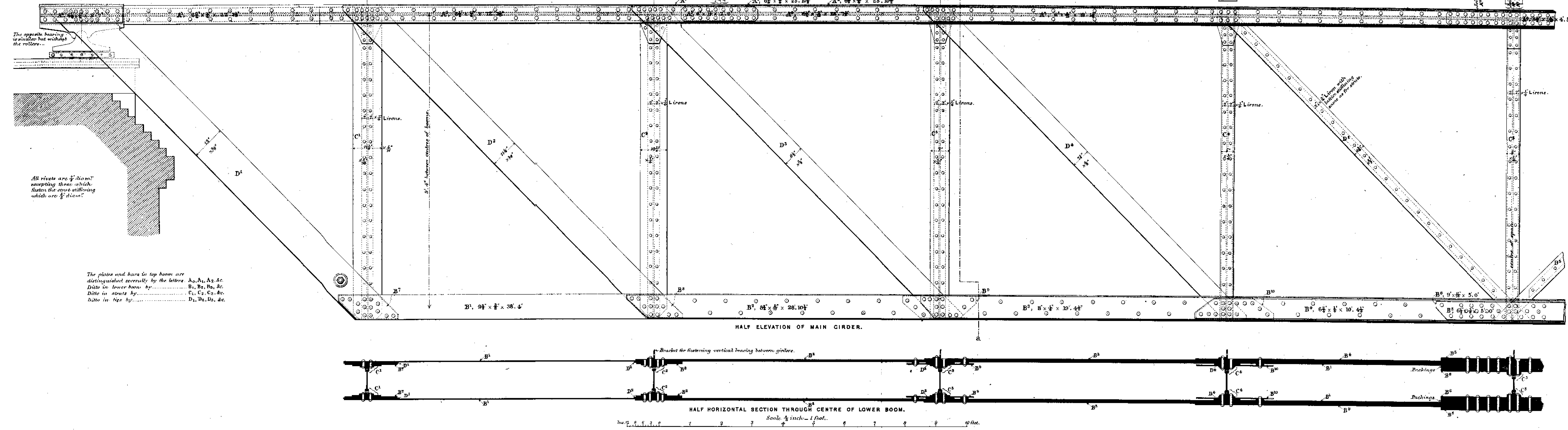




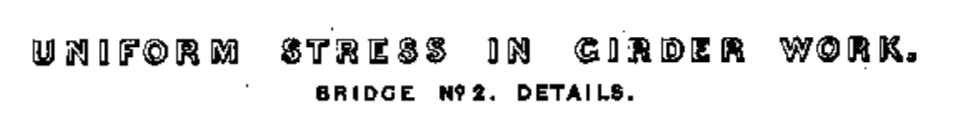




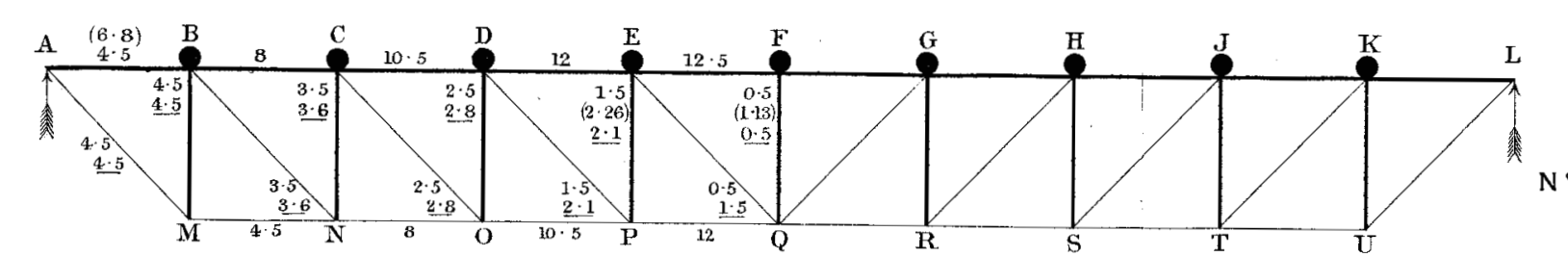

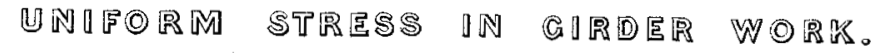
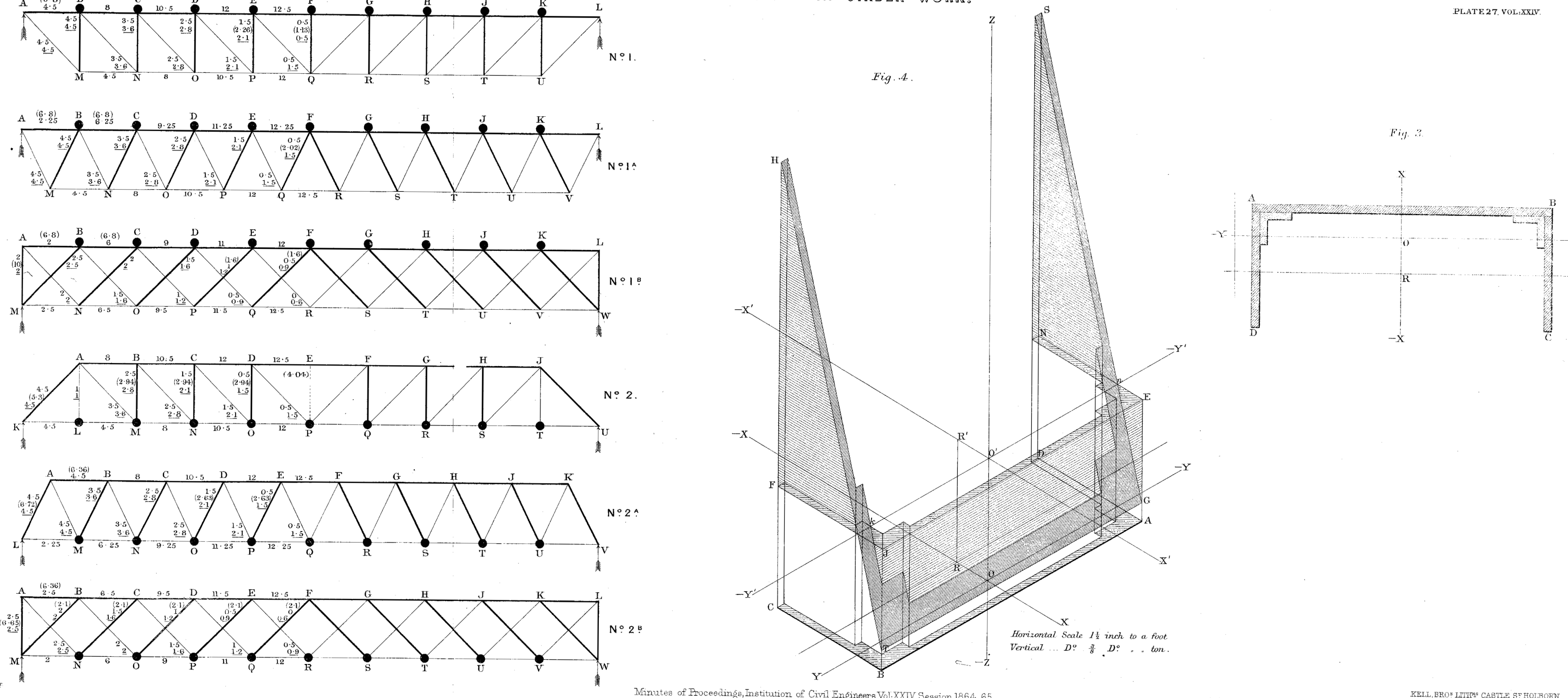